\title{
Multi-Objective Artificial Bee Colony Algorithms and Chaotic- TOPSIS Method for Solving Flowshop Scheduling Problem and Decision Making
}

\author{
Monalisa Panda \\ Department of Computer Science and Information Technology, Siksha 'O' Anusandhan Deemed to be University \\ Bhubaneswar, 751030, Odisha, India \\ E-mail: monalisapanda.iter@gmail.com \\ Satchidananda Dehuri \\ Department of Information and Communication Technology, Fakir Mohan University \\ Vyasa Vihar, Balasore, 756019, Odisha, India \\ E-mail: satchi.lapa@gmail.com \\ Alok Kumar Jagadev \\ School of Computer Engineering, KIIT Deemed to be University \\ Bhubaneswar, 751024, Odisha, India \\ E-mail: alok.jagadev@gmail.com
}

Keywords: flowshop scheduling, multi-objective optimization, local search algorithms, artificial bee colony algorithm, multi-criteria decision making, chaotic-TOPSIS.

Received: December 13, 2018

\begin{abstract}
Retrieval of optimal solution(s) for a Permutation Flow-Shop Scheduling Problem (PFSSP) within a reasonable computational timeframe has been a challenge till yet. The problem includes optimization of various criteria like makespan, total flowtime, earliness, tardiness, etc for obtaining a set of Pareto solutions in the process of Multi-Objective Optimization (MOO). This paper remodels a Discrete Artificial Bee Colony Algorithm (DABC) from a single objective optimization method to a multiobjective optimization one to solve the PFSSP executed and explored through the alternative and combined use of two local search algorithms named as: Iterated Greedy Search Algorithm (IGRS) and Iterated Local Search Algorithm (ILS). The algorithm has been classified into three different scenarios raised with the analysis of time complexity measure of applied local search methods prioritized through the insertion and swap operation of neighborhood structures that intensifies the local optima in the search space. The results of the DABC algorithm are summarized with respect to Total Completion Time (TCT), Mean Weighted Tardiness (MWT), and Mean Weighted Earliness (MWE). Based on the time complexity measure of the obtained results a Multi-Objective Artificial Bee Colony Algorithm (MOABC) has been proposed by adopting the simplest local search method of all in order to reflect the enhanced version of previously remodeled DABC algorithm. Finally, we propose a Chaotic based Technique for Order of Preference by Similarity to Ideal Solution (Chaotic-TOPSIS) using a suitable chaotic map for criteria adaptation in order to enhance the decision accuracy in the multi-Criteria Decision Making (MCDM) domain.

Povzetek: Članek se ukvarja z NP problemom večkriterijske optimizacije izdelave urnika z imenom Permutation Flow-Shop Scheduling Problem (PFSSP). Uvede Multi-Objective Artificial Bee Colony Algorithm (MOABC), tj. več-kriterijski algoritem z umetno čebeljo kolonijo in pokaže izboljšane rezultate.
\end{abstract}

\section{Introduction and related work}

The flowshop scheduling problem (FSSP) is a combinatorial optimization problem, inheriting the ideas from Barkers sequencing problem [1] that is based on ordering of jobs to determine a schedule. However, the problem is NP-hard and introduced by Johnson in 1954 [2]. It has a wide application in logistic, industrial, and many other fields. It aims to find the minimal total flow time (TFT) or total completion time (TCT) execution. The permutation flowshop scheduling problem (PFSSP) is a particular case of FSSP, consisting of a set of $n$ jobs which should be processed in the same order as to the available $m$ machines. The goal is to find the best permutation of jobs that would result best minimal TCT execution of all the processes subject to the constraints that each job is independent, and available for processing at time zero. From time zero onwards, each machine is continuously available and is able to process one operation at a time. Each job can be manufactured at a 
specific moment on a single machine. When a machine is not available, automatically the jobs remaining are queued to a waiting state. An ongoing job, in a machine is not interrupted till completion.

During the last decades, the research attention for combinatorial optimization has turned to hybrid systems. It is observed that combination of different features from various optimization heuristics results in more robust and unique combinatorial optimization tools. Since the pioneering work of Johnson [2], a number of heuristics have been approached for solving FSSP. These proposed heuristics can be specified either as constructive or improvement. Most constructive heuristics [3-7] are the extended version of the Johnson's algorithm [2], based on two or three-machine flowshop problems. In his work Palmer [3] developed a slope order index for sequencing the jobs with some allotted machines and processing times. A little variation to Palmer's algorithm was proposed by Gupta [4] in order to estimate the same slope index. Also a lot many variants of branch and bound algorithms were developed subsequently [8-11] in this regard. Ignall and Scharge [10] applied the branch and bound scheme for the first time, based on two lower bounds in the two-machine FSSP. Bansal [8] extended the proposed idea to an $m$-machine case.

Due to the essence of optimizing multiple objectives in PFSSP, it is also extended to the multi-objective domain with many challenging approaches (non-heuristic and meta-heuristic). Selen and Hotts [12] solved a multiobjective flowshop scheduling problem (MOPFSSP) with $\mathrm{m}$-machines by formulating a mixed-integer goal programming model with two objectives that is makespan and mean flowtime. Wilson [13] proposed an alternative model for it, by considering a fewer number of variables but at the same time he has added large number of constraints to it. Both the models have included same number of integer variables. Daniels and Chambers [14] proposed a branch and bound approach with two objectives (makespan and maximum tardiness) where they computed the Pareto solution for a 2-machine flowshop scheduling problem. Rajendran [15] also presented a similar procedure along with two heuristic approaches for the 2-machine flowshop scheduling problem with two objectives: minimization of TFT subject to optimal makespan. Similarly two different methodologies (one is based on a Branch and Bound (B\&B) technique of exact algorithms and other one is based on Palmer approach of heuristic algorithms) are used [16] to find the optimum solution for minimization of bi-criterion (makespan, weighted mean flowtime) objective function of three machines FSSP with transportation times and weight of the jobs. Recently a production scheduling problem in hybrid shops has been solved by Mousavi et al.[17], by assuming some realistic assumptions.

Like the non-heuristics, many meta-heuristic methods like trajectory based and population based methods have also been proposed to solve MOPFSSPs. Chakravarthy and Rajendran [18] proposed a simulated annealing (SA) algorithm for resolving the $m$-machine FSSP to minimize makespan and maximum tardiness.
Similarly many SA algorithms [19-21] were proposed to optimize various objectives like makespan, TFT, and total tardiness. Another SA algorithm was approached by Loukil et al. [22] based on $m$-machine case. The algorithm assumed objective pairs out of a number of objectives such as: average weighted completion time, makespan, average weighted tardiness, maximum earliness, maximum tardiness, and the number of tardy jobs. A novel multi-objective memetic search algorithm (MMSA) [23] is proposed to solve the MOPFSSP with makespan and total flowtime. The performance of the algorithm is validated and compared with the four stateof-the-art algorithms on a number of benchmark problem and provides better solutions than these compared algorithms. Another novel fuzzy multi-objective local search-based decomposition algorithm has been approached for solving a fuzzy-MOPFSSP for two fuzzy objectives, that is, the fuzzy makespan and the fuzzy total flow time. An extensive computational study on Taillard benchmarks has been conducted to compare the proposed algorithm with the fuzzy NSGAII and the results demonstrate the effectiveness of the proposed algorithm [24].

Among meta-heuristics, swarm intelligence has created a class of its own, which models the collective behavior of self-organized models and applies these models to solve many complex problems. Earlier works have adopted ant colony optimization (ACO) and particle swarm optimization (PSO) algorithms to simulate the swarm behavior of ant colonies and flocks of birds, respectively. There are a few researches which implements the PSO and ACO for solving the MOPFSSP [25-29] subject to makespan, TFT and completion time variance. Recently, a lot many algorithms have been proposed by modeling the intelligent behaviors of real bee swarms in this regard. The emerging research with artificial bee colony algorithms (ABC) demonstrates that these algorithms outperform and is equally competitive as compared to other population-based algorithms with the advantage of employing fewer control parameters [30-35]. Sharma et al. [36] provided a state art survey of $\mathrm{ABC}$ algorithm and its performance analysis with different size of population. Singh [37] has explained how one can solve different optimization problems using ABC algorithm. Recently, Amlan et al.[38] applied a Regional Flood Frequency Analysis (RFFA) to 33 stream gauging stations in the Eastern Black Sea Basin, Turkey. Tereshko [39] proposed a DABC algorithm for the FSSP with intermediate buffers (IBFSP) in order to minimize the maximum completion time. The DABC algorithm uses the effectiveness of the insertion and swap operators to produce neighbourhood solutions at the employed bee phase. From many such articles [40-42] it is clearly understood that, swarm intelligence provides a better algorithmic framework inspired by the intelligent behaviour of the animals, birds and social insects.

The earlier work of PFSSP solved using DABC algorithm, mainly focuses on optimization of TCT criterion. As the DABC algorithm uses many strategies to find the nearest solutions in the search space, no detailed work has been done that counts the time 
complexity of the algorithm. To deal with this, we have remodelled the DABC algorithm of Tasgetiren et al.[43] for three different cases by the application of some effective strategies. The proposed algorithm is inherited with the hybridization of swap/insertion operations and construction-destruction procedures for the neighbourhood structures known as iterated local search (ILS) and iterated greedy search algorithm (IGRS) respectively. Through an experimental analysis, the proposed algorithmic cases are evaluated for best CPU time utilization with respect to three objectives such as: TCT, weighted mean tardiness (WMT), and weighted mean earliness (WME). Again in the same scenario we have tested the results of canonical $\mathrm{ABC}$ against DABC algorithm. Genuinely due to multiple objectives, here $\mathrm{ABC}$ has been turned to multi-objective $\mathrm{ABC}$ (MOABC) with necessary improvements to solve the MOPFSSP.

While working with multiple-objectives it is almost impossible to get a single compromising solution. The situation leads to a multi-criteria decision making (MCDM) scenario. MCDM is the most powerful branch of decision making: generally handles multiple objective functions together and includes a lot many approaches that have been applied to different problem domains to choose the best alternative. But major parameters like criterion weight in these methods are founded on randomness of data. Mareschal [44] has claimed that proper weight assignment to each criterion will lead to a better and more appropriate decision making framework for both qualitative and quantitative data. However, the weight assignment procedure (specifically to qualitative criteria) is completely dependent upon the decision maker's preference and varies remarkably from one decision maker to other. This paper proposes TOPSIS using chaotic maps for generating random numbers during criteria adaptation to improve the decision accuracy. The chaotic number generators emerges a random number each time when needed by the decision maker to define the criterion weight. To maintain the criterion preference, we have sorted the random numbers and assigned them accordingly.

The remaining parts of the paper are assembled as follows. Section 2 presents the problem formulation and assumptions. The canonical ABC and DABC algorithm has been illustrated in Sections 3 and 4 and Section 4 also represents the details of the ILS algorithm and IGRS algorithm applied in MOPFSSP. Section 5 encloses the multi-objective ABC for PFSSP. Section 6 contains the computational results for both algorithms with two different synthetic datasets. Decision making using chaotic-TOPSIS is illustrated in section 7. Section 8 concludes the article with future directions.

\section{Problem description and assumptions}

A PFSSP is consisting of $n$ jobs $\left(\Pi_{1}, \Pi_{2}, \Pi_{3} \ldots \ldots . . \Pi_{n}\right)$, each having $m$ number of tasks, that have to be processed in separate machines. A schedule for the jobs is the assignment of tasks to time intervals on the available machines. Task $T_{j i}$ must be assigned to machine $j$ where the task belongs to job $i$, additionally for any job $i$, the processing of task $T_{j i}$ cannot be started till $T_{j i-1}$ has been completed.

Where,

$i \epsilon(1, n)$ and $j \epsilon(1, m)$.

$\mathrm{O}_{j k}=$ processing time of job $j$ on machine $k$.

\section{Assumptions}

(i) Jobs consist of a pre-ordered sequence of operations.

(ii) At a time only one job can be processed on one machine.

(iii) The job orderings are same for all machines.

(iv) Timeslot of different job operations is predetermined.

(v) Once a job starts being processed on the first machine, cannot be interrupted in between either on or between machines.

(vi) Release time of all jobs is zero.

As per above stated assumptions, a dummy PFSSP; having ' 3 ' jobs, each with ' 3 ' operations having some random processing time can be executed in ' 3 ' different machines as follows:

With regard to the above context: $F\left(\Pi_{j}\right)$, the flowtime of job $\Pi_{j}$ is same as the completion time $C\left(\Pi_{j}\right.$, $m$ ) on the machine $m$. So the total completion time (TCT (п)) of all jobs is equal to maximum of flow time or completion time of all jobs and is calculated as:

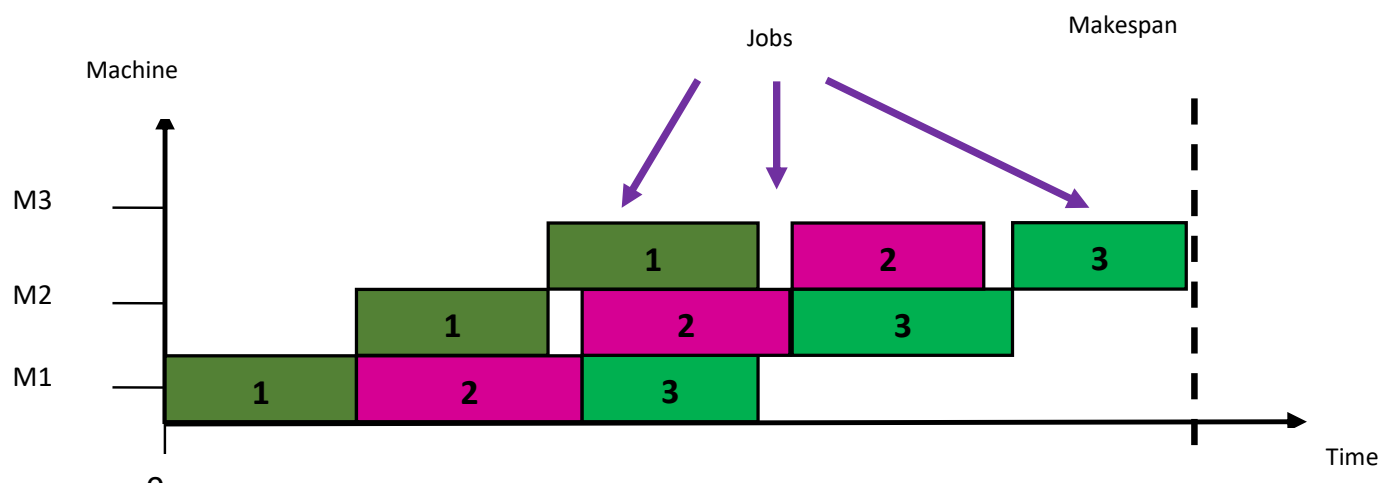

Figure 1: A dummy PFSSP. 


$$
\operatorname{TCT}(\pi)=\max \sum_{j=1}^{n} F\left(\pi_{j}\right)=\max \sum_{j=1}^{n} C\left(\pi_{j}, m\right)
$$

Similarly let $D_{j}$, be the due date and $C_{j}$ the completion time of job $j$, for $j \epsilon n$. The jobs earliness and tardiness can be computed by, $E_{j}=\max \left\{D_{j}-C_{j}, O\right\}$ and $T_{j}=\max \left\{C_{j}-D_{j}, O\right\}$ respectively. Hence the weighted mean tardiness and weighted mean earliness of different job sequence can be calculated as:

$$
\begin{aligned}
W M E^{e} & =\frac{\sum_{j=1}^{n} \max \left[D_{j}-C_{j} ; 0\right] e_{j}}{\sum_{j=1}^{n} e_{j}} \\
W M T^{R} & =\frac{\sum_{j=1}^{n} \max \left[C_{j}-D_{j} ; 0\right] r_{j}}{\sum_{j=1}^{n} r_{j}}
\end{aligned}
$$

where,

$$
\begin{aligned}
& n=\text { number of jobs } \\
& j=\text { job index } \\
& D_{j}=\text { due date of job } j . \\
& C_{j}=\text { completion time of job } j . \\
& A_{j}=\text { arrival time of job } j \text { in the shop. } \\
& e_{j}=\text { earliness cost per unit time for job } j \\
& r_{j}=\text { tardiness of job } j \text { penalty per unit time. }
\end{aligned}
$$

\section{Canonical ABC algorithm}

$\mathrm{ABC}$, a member of swarm intelligence is a meta-heuristic algorithm based on the intelligent behavior of honey bees, introduced by Karaboga [30, 34-35, 45]. Due to its simplicity and good performance reported in various fields while optimizing both single and multi-objective problem, we motivated to extend its usage in PFSSP. It is inspired by the nature that is by the foraging behavior of real honey bees, their self-organization capability, and specially division of labor features. The canonical ABC algorithm has some essential components like food sources, nectar-amount in each source, and three kinds of foraging honey bees (employed bee, onlooker bee, and scout bee). Here every food source signifies a candidate solution in the search space and the fitness of these solutions is equivalent to the nectar-amount of those food sources. Employed bees go on searching random food positions; they also share the collected information about food sources among the onlooker bees through the waggle dance. Onlooker bees select the better sources (better solutions) with high nectar amount (high fitness value), based on the information (fitness value) from the employed bees. Scout bees are those employed bees which could not found remarkable food sources. The pseudo-code of canonical $\mathrm{ABC}$ is given below.

\author{
Initialize population $(P)$ \\ Fitness evaluation ( $f$ ) \\ While (cycle $<=$ maximum number of cycle) \\ \{ \\ Employed bee phase \\ \{ \\ Produce neighborhoods \\ Fitness evaluation selection ( $f$ i) \\ Probability calculation $\left(p_{i}\right)$ \\ \} \\ Onlooker bee phase \\ \{ \\ Select a solution based on probability $p_{i}$ \\ Produce new solution \\ Fitness evaluation \\ Greedy selection procedure \\ \} \\ Scout bee phase \\ \{ \\ Replace the abandoned one \\ \} \\ Memorize the best \\ cycle ${ }^{++}$ \\ \}
}

\section{Modified discrete artificial bee colony algorithm}

Though ABC algorithm is a proved continuous optimizer for various combinatorial optimization problems, later has also shown its efficiency towards discrete version of it. Here, we use a modified version of the above ABC algorithm to handle discrete decision variables. We have extended the single objective problem of Tasgetiren et al. [43] to a multi-objective one and the detailed of modified $\mathrm{DABC}$ has been discussed below:

\section{Initialization:}

The population is initialized with a random set of solutions, each consisting with a random permutation of jobs.

$$
\Pi=\left(\Pi_{1}, \Pi_{2}, \Pi_{3} \ldots \ldots . . \Pi_{n}\right)
$$

\section{Employed bee phase:}

According to the basic ABC algorithm, the employed bees generate their neighborhood nectar sources. Here for obtaining the nearer food sources, we will take the advantage of the adopted strategies from IG_RS algorithm and ILS [43]. From IG_RS algorithm we have borrowed the concept of construction and destruction procedure and the two common operators named insert and swap are being inherited from ILS. Each one of these is used for determining the neighboring solutions in the search space. In order to evaluate their performances, we will adopt three different cases with the alternative and combined use of these operators (insert and swap) and procedures (destruction- construction). For suitability, we named each these cases of DABC algorithm 
separately as DABC-I, DABC-II and DABC-III respectively. This step attempts to improve the population deterministically by accepting the improved adjacent solutions by examining their fitness values. The solutions to next step are chosen on the basis of equal number of best solutions from each objective respectively to maintain the population diversity.

\section{Case I:}

Each nearest solution in the population is determined by any one of the following strategy. The selected strategy is applied two times separately to each permutation $\Pi$ in the population, resulting two nearest neighbors and the best one is selected to the next step.

(i) Applying two-insert moves to a permutation $\Pi$ with $p=2$.

(ii) Applying three-insert moves to a permutation $\Pi$ with $p=3$.

(iii) Applying two-swap moves to a permutation $\Pi$ with $p=2$.

(iv) Applying three-swap moves to a permutation $\Pi$ with $p=3$.

Case II:

Each nearest solution is chosen by applying any of the following strategy.

(i) Applying two-insert moves to a permutation $\Pi$ with $p=2$.

(ii) Applying three-insert moves to a permutation $\Pi$ with $p=3$.

(iii) Applying two-swap moves to a permutation $\Pi$ with $p=2$.

(iv) Applying three-swap moves to a permutation $\Pi$ with $p=3$.

(v) Applying one destruct-construct procedure to a permutation $n$ with destruction size $x$.

Case III:

The nearest solutions are determined by using the following strategy.

(i) Applying destruct-construct procedure to a permutation $n$ with destruction size $x$

\section{Onlooker bee phase:}

This phase selects a food source based on the probabilities obtained from the fitness values during employed bee phase. The aim of this phase is to find further better compromising solutions by applying well devised local search. The probabilistic selection can be described as:

$$
p_{i}=\frac{f i t_{i}}{\sum_{j} f i t_{j}}
$$

Here $f i t_{i}$ is defined as the fitness value of the $i^{\text {th }}$ solution compared to other solutions in the solution set. The solutions with a higher probability are always selected to the next cycle. In addition to this, almost an equivalent strategy to that of employed bee phase is employed during the onlooker bee phase to produce a new neighborhood solution. An efficient local search method has to be applied to further improve the candidates of the onlooker bee phase. A better food source has to replace the current one and become a new member in the population; else both are treated as nondominated to each other.

\section{Scout phase:}

In general, the scout bee phase removes the abandoned solutions (worst solutions) from the search space and tries to discover new ones with better fitness value. Therefore, the DABC algorithm removes a defined number of worst solutions and replaces them with new ones by the process of tournament selection in order to deal with local optima by avoiding the trial counter.

During the evolution process, the solutions will be prioritised with respect to TCT, WMT and WME. Also the different cases of the employed bee phase will fall to different CPU utilization of the algorithm. As per the selection of basic ABC algorithm, an old solution is replaced by a new one if it is found to be superior in all objectives by using a greedy selection procedure.

A common framework for DABC-I, DABC-II, and DABC-III as follows:

[Initialization]

$$
\pi=\pi_{1}, \pi_{2}, \pi_{3}, \ldots \ldots \ldots \ldots \pi_{N}
$$

[Fitnesscalculation]

$$
\begin{aligned}
& \text { for }(i=1 \text { to } N) \\
& \text { Calculate } f\left(\pi_{i}\right)
\end{aligned}
$$

[Employedbee phase]

$$
\begin{aligned}
& \text { for }(i=1 \text { to } N) \\
& \pi^{\text {new }}=\text { local_search }(\pi) \\
& \text { for }(\text { objetivel to } M) \\
& \pi=\text { propertionate-bestsequence }\left(\pi^{\text {new }}, \pi\right)
\end{aligned}
$$

[onlookerbee phase]

$$
\begin{aligned}
& \text { for }(i=1 \text { to } N) \\
& \pi^{\text {new }}=\text { local_search }(\pi) \\
& \text { for(objetivelto } M)
\end{aligned}
$$

$$
\pi=\text { propertionate-bestsequence }\left(\pi^{\text {new }}, \pi\right)
$$

\section{[Scoutbee phase]}

$$
\begin{aligned}
& \text { for }\left(\pi=\pi_{1}, \pi_{2}, \pi_{3}, \ldots \ldots \ldots \ldots . . . \pi_{N}\right) \\
& \text { replace abandonedsolutions }
\end{aligned}
$$

$\operatorname{return}(\pi)$

Figure 2: DABC algorithm

\subsection{Local search methods: IG_RS algorithm and ILS algorithm}

The insert operator eliminates a job from the job pool (position $r$ ) and reinserts it into another position $(q)$ in the same pool that is in the permutation $\Pi$, such that $q \epsilon(r$, $r-1)$ and the swap operator simply interchanges the position of two random jobs in a permutation $\Pi$. Similarly the destruction- construction procedure of IG_RS 
algorithm reconstructs a job pool by assigning best positions to a sub part of the original job sequence. Here the destruction phase randomly removes $x$ number of jobs from the permutation $\Pi$ without repetition resulting two partial solutions $\Pi_{x}(x$ number of jobs $)$ and $\Pi_{x} x^{\prime}\left(x^{\prime}=n-x\right.$ number of jobs). Then the construction phase adds each removed jobs back to the pool in the same order by searching its best position. The motivation of using the above methodologies in our algorithm is inherited from the efficacy of the DABC algorithm. Here the focused parameters are: perturbation strength $p$ and the

$$
\begin{aligned}
& \text { Procedurelocal_search }(\pi) \\
& \pi=\pi_{1}, \pi_{2}, \ldots \ldots \ldots . \pi_{N} \\
& \pi^{\text {new }}=N u l l \\
& \text { for }(i=1 \text { to } N) \\
& \operatorname{for}(j=1 \text { to } N) \\
& \pi^{\prime}=\pi_{i} \\
& \pi^{\prime \prime}=\left\{\begin{array}{l}
\text { insertlocd_search }(\pi) \\
\operatorname{swaplocal} \_ \text {search }(\pi) \\
\text { destructconstructlocal_search }(\pi)
\end{array}\right. \\
& \text { if } f\left(\pi^{\prime \prime}\right)<f\left(\pi^{\prime}\right) \\
& \pi_{j}^{\text {new }}=\pi \\
& \text { else } \\
& \pi_{j}^{\text {new }}=\pi \\
& j=j+1 \\
& \text { endif }
\end{aligned}
$$

end for

$$
i=i+1
$$

end for

$\operatorname{return}\left(\pi^{\text {new }}\right)$

$$
\text { \} }
$$

Figure 3: Local_search procedure.

$$
\begin{aligned}
& \operatorname{procedureswaplocal} \_\operatorname{search}(\pi) \\
& \operatorname{rand}(i, j) \\
& \operatorname{swaplocal} \_\operatorname{search}(\pi, i, j) \\
& \operatorname{return}(\pi)
\end{aligned}
$$

Figure 4: Swap local-search procedure.

\author{
procedureinsertlocd_search $(\pi)$ \\ $\operatorname{rand}(i, j)$ \\ insert $(\pi, i, j)$ \\ $\operatorname{return}(\pi)$ \\ end procedure
}

Figure 5: Insert local_search procedure. proceduredestructconstruct $(\pi, d)$

$\pi^{D}=\pi^{R}=\operatorname{destruct}_{d}(\pi)$

$\pi=\operatorname{construct}\left(\pi^{D}, \pi^{R}\right)$

$\operatorname{return}(\pi)$

end procedure

Figure 6: Destruct-construct procedure.

destruction size $x$ that has to be carefully chosen. A perturbation is achieved by a random insertion of a job to another position or by swapping of some jobs randomly in a permutation $\Pi$. Similarly choosing a larger destruction size for $x$ will lead to a better result and a smaller one will be good for CPU time minimization. Tasgetiren et al. [43] have considered the perturbation values are as 1 or 2 and the $\mathrm{x}$ values as 8 or 12 for different instances of Taillard [46]. However in our work, we have considered two synthetic datasets for small and large sized systems with variable number of jobs and machines. Here the $p$ values are considered as 2 or 3 and the $x$ values are considered as 2 (for small sized) and 4 (for large size) respectively.

\section{MOABC for MOPFSSP}

The above proposed DABC algorithm is the direct extension of single objective DABC proposed by Tasgetiren et al. [43]. The algorithmic framework and search for local optima is much more flexible and effective with the advantages of local search algorithms in the DABC algorithm. To achieve a more accurate and efficient problem solving approach in the field of multi objective optimization; we have simulated these advantages to model a multi objective Pareto-based ABC algorithm with same objectives to solve the FSSP. The proposed MOABC algorithm combines the main idea of ABC with the above local search strategy to search the neighborhood structure. To apply the local search algorithm in the next proposed one, we have adopted one of the simpler one i.e., the swap () local-search instead of using all methods randomly. Firstly the proposed MOABC algorithm initiates a number of randomized job sequences of $n$ jobs, and is stored in the population matrix. These sequences represent the random food sources of $\mathrm{ABC}$, with certain quality and diversity. Secondly, an exploitation search procedure for the first two bee phases (employed and onlooker) is designed to best suit the problem and to intensify the local search operation. To record the updated non-dominated sequence emerged in each cycle, it uses a Pareto-based 
archive set. In addition, the population is well-adjusted to maintain diversity in scout bee phase by eliminating the worst solutions. It is seen that proposed algorithm is able to find the best set of solutions and a proper statistical analysis has also been done to evaluate the proposed algorithm's performance with different inputs. Some important terms related to MOABC can be defined below.

\section{Pareto dominance}

Any solution $S^{\prime}$ is said to be non-dominated to $S^{\prime \prime}$ if and only if,

(i) (i) The solution $S^{\prime}$ is no worse than $S^{\prime \prime}$ in all the objectives.

(ii) The solution $S^{\prime}$ is strictly better than $S^{\prime \prime}$ in at least one objective.

Pareto optimal solution set and Pareto optimal front

Pareto optimal solution set is the group of all Pareto optimal solutions, and the respective graphical representation in the objective space is known as the Pareto optimal front.

Archive

An archive records the track of the non-dominated solutions from time to time. It is iteratively updated throughout the search procedure. Once a new nondominated solution generated, the archive is updated accordingly.

\subsection{Problem formulation}

The FSSP is rescheduled (fixed to similar assumptions as stated above) with the same three defined criterions (TCT, WMT and WME) and $n$ jobs to be solved with ABC. As we know mostly there will be multiple solutions, non-dominated to one another will be emerged during the simultaneous optimization of multiple objectives (known to discover true Pareto front), we have done a straight forward extension of uni-objective $A B C$ as well as above DABC to redesign an MOABC algorithm. In the employed bee phase, an exploitation search procedure is applied on the initialized solutions, to derive the non-dominated solution set. The generated Pareto front is maintained in an archive with the corresponding trial counters and will be updated from time to time. Onlooker bees search for more intensified solutions within the neighborhood of the food source in their memory. Finally, the abandoned solutions are deleted from the archive to stand with a best fitted Pareto front.

\subsection{Architecture}

As per the problem architecture, ' $n$ ' jobs are divided into ' $m$ ' number of tasks, to be sequenced differently and to be processed in different machines. Each job sequences are evaluated through their fitness values against the individual objective functions. After the problem evaluation, the resulted sequences are listed out that are non-dominating to each other. Figure 7 is representing the MOPFSSP problem architecture which needs to be optimized to a set of optimal job sequences as corresponding non- dominated set.

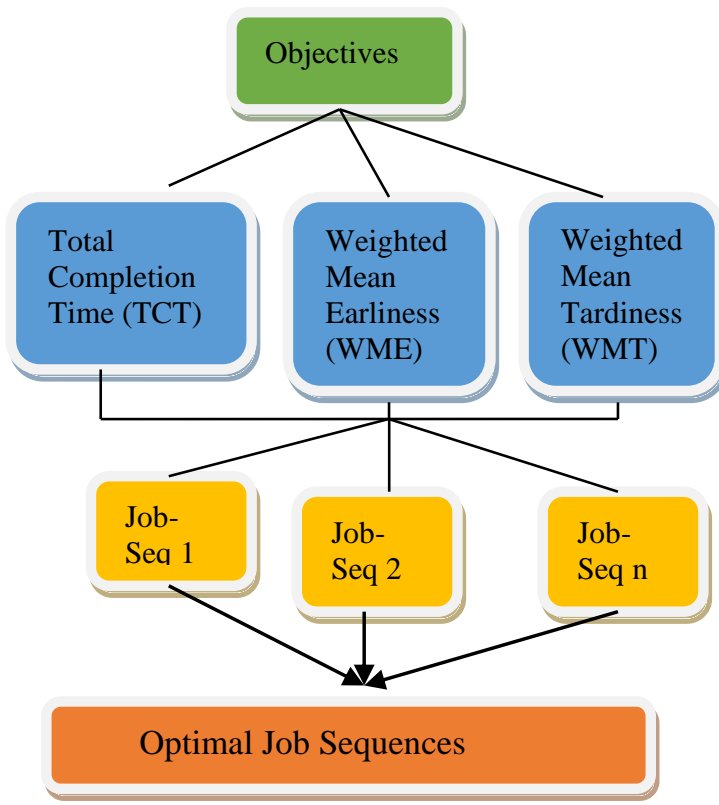

Figure 7: MOPFSSP architecture.

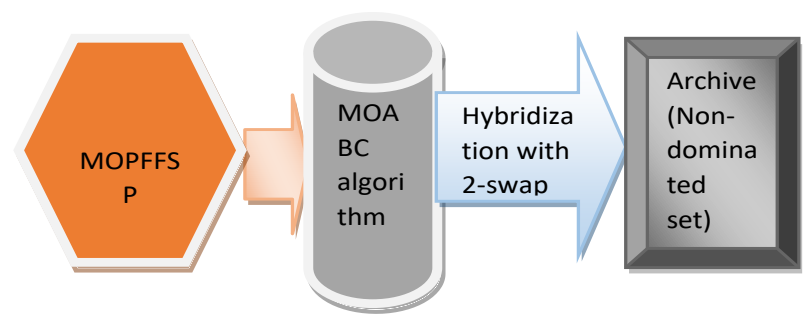

Figure 8: Proposed framework using MOABC.

Figure 8 is represents the proposed solution strategy using MOABC. The proposed model generates multiple Pareto optimal solutions iteratively which are updated in an external archive time to time. Here the algorithm adopts the 2 swap () local search strategy to generate the neighborhood structures in the solution space. The selection of the same local search procedure is based upon the time complexity analysis of all considered methods in the remodeled DABC algorithm.

\subsection{Proposed MOABC}

This section presents the algorithmic representation of proposed MOABC algorithm to solve MOPFSSP.

The derived MOABC algorithm, initializes the population ' $\Pi$ ' with ' $n$ ' solutions, each consisting of a random number of job sequences similar to the DABC algorithm. Each updated solutions in the population matrix are evaluated for the corresponding fitness value using the objective functions 1 - 3 . The generated nondominated set is maintained in an archive with the corresponding trial counters; which is updated in every cycle. Employed bees explore for better sources in the neighborhood by applying swap () operation, where two randomly selected jobs $i$ and $j$ (two random selected dimensions) for a random solution (sequence) $k$ are 


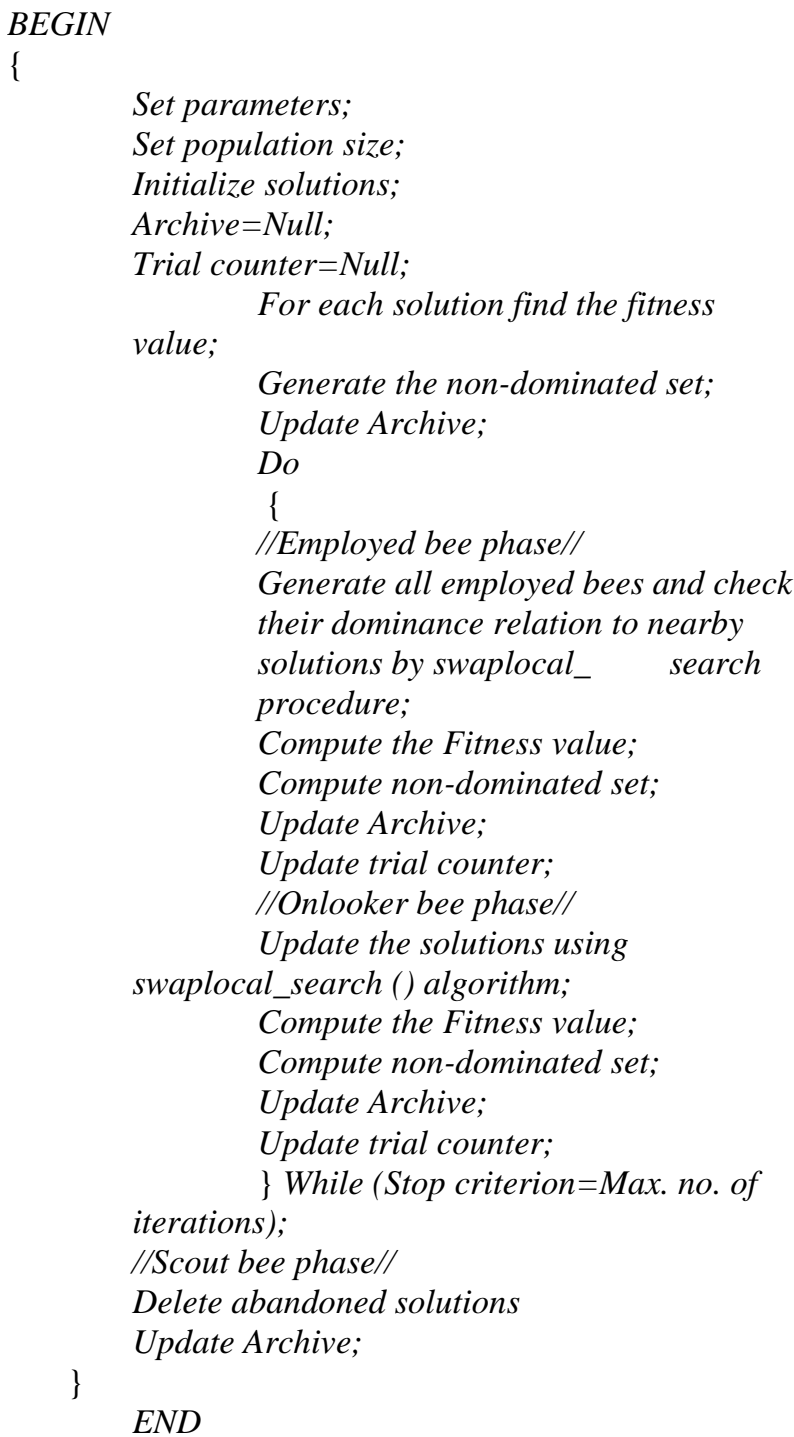

Figure 9: MOABC pseudo code.

swapped with each other. Onlooker bee selects a candidate source depending on its probability values calculated and provided by the employed bees. The solutions with a greater probability are shifted to the archive. Within a defined number of cycles, the employed bees whose solutions cannot be further improved (through a predetermined number of trials) are treated as abandoned ones and are deleted permanently from the archive. These abandoned solutions are calculated by the help of trial counters. If a solution in $S$ is improved by the corresponding solution in $S^{\prime}$ then the trial counter is set to zero (0), else it is set to one (1).

\section{Numerical simulation}

The numerical results represent the performance of both $\mathrm{DABC}$ algorithm and $\mathrm{MOABC}$ algorithm respectively with respect of TCT, $\mathrm{WME}^{\mathrm{e}}$ and $\mathrm{WMT}^{\mathrm{r}}$. Two different datasets have been initialized with little parameter variation. One of this has been initialized with small processing times and due dates named as 'small-size dataset' and the other one is named as 'large-size'. For

both the proposed algorithms, we have considered similar input datasets.

\subsection{Control parameters}

However both the algorithms require same control parameters except the case of abandoned solution. The DABC algorithm removes a defined number of worst solutions and replaces them with new ones in order to remove abandoned solutions from the population where as the MOABC algorithm removes those solutions based on a trial counter limit.

\subsubsection{Parameters of DABC}

$\begin{array}{lc}\text { Parameters: } & \text { Values: } \\ \text { Population size } & 10 \\ \text { Maximum iterations } & 50 \\ \text { Number of onlookers } & 1 / 2 *(\text { colony size }) \\ \text { Number of employed bees } & 1 / 2 * \text { (colony size) } \\ \text { Worst solutions to be replaced } & 2 \text { or } 4\end{array}$

\subsubsection{Parameters of MOABC}

Parameters:

Colony size

Maximum iterations

Number of onlookers

Number of employed bees

Limit for abandoned solution

\subsection{Description of the numerical data}

To evaluate DABC-I, DABC-II and DABC-III, two instances of datasets are customized with two different combinations of jobs and machines. With a little parameter variation both the datasets consider same population size of 10. The due date of each job is initialized separately with respect to two datasets. We have assigned same weight for both tardiness and earliness in both the input sets, while evaluating $\mathrm{WME}^{\mathrm{e}}$ and $\mathrm{WMT}^{\mathrm{r}}$. Again the same datasets are used to characterise the performance of MOABC.

\subsubsection{Small-size data}

To validate the results at an eye, a small size dataset is randomized with a combination of 4 jobs and 3 machines with an ideal parameter setting. The processing time $\left(\mathrm{O}_{\mathrm{ik}}\right)$ of the jobs are set within $[0,5]$ and the due times are set in $[10,15]$. The earliness and tardiness weights are considered in the range $[1,10]$. Based on the due time, the calculated TCT and the weights (earliness and tardiness), the MWT and MWE of the jobs have to be calculated. The destruction size has been assumed as 2 . All these parameters, input data, corresponding statistics and the initial population sequence are tabulated below. 


\begin{tabular}{|l|l|l|l|l|}
\hline & Job 1 & Job 2 & Job 3 & Job 4 \\
\hline Machine 1 & $\mathrm{O}_{11}=4$ & $\mathrm{O}_{12}=1$ & $\mathrm{O}_{13}=5$ & $\mathrm{O}_{14}=2$ \\
\hline Machine 2 & $\mathrm{O}_{21}=3$ & $\mathrm{O}_{22}=2$ & $\mathrm{O}_{23}=4$ & $\mathrm{O}_{24}=3$ \\
\hline Machine 3 & $\mathrm{O}_{31}=5$ & $\mathrm{O}_{32}=2$ & $\mathrm{O}_{33}=3$ & $\mathrm{O}_{34}=4$ \\
\hline Due time & 10 & 12 & 30 & 15 \\
\hline Weight & 2 & 3 & 4 & 2 \\
\hline
\end{tabular}

Table 1: Processing time of machine vs task of each job.

\begin{tabular}{|l|c|c|r|}
\hline Jobs & Minimum & Maximum & $\begin{array}{c}\text { Standard } \\
\text { deviation }\end{array}$ \\
\hline 1 & 3 & 5 & 0.81 \\
\hline 2 & 1 & 2 & 0.47 \\
\hline 3 & 3 & 5 & 0.81 \\
\hline 4 & 2 & 4 & 0.81 \\
\hline
\end{tabular}

Table 2: Statistics of the small-size dataset.

\section{Parameter setting}

(i) $\quad O_{j k}:[1-5]$

(ii) Weight (tardiness and earliness): $[1,10]$

(iii) Population size: 10

(iv) Destruction size: 2

(v) Due time: [10, 15]

Table 1 represents the processing time of 4 different jobs with respect to 3 machines. Also it initializes the expected finish time of each job and an assigned weight which will be further used to calculate the fitness value of the defined objective functions.

Table 2 contains the statistical analysis of standard deviation for each job( small-sized dataset).To calculate the standard deviation we have summarized the minimum and maximum processing time of each job

\begin{tabular}{|c|c|c|c|c|}
\hline Population & \multicolumn{4}{|c|}{ Job sequence } \\
\hline 1 & $\mathrm{~J}_{0}$ & $\mathrm{~J}_{1}$ & $\overline{J_{2}}$ & $\overline{J_{3}}$ \\
\hline 2 & $\mathrm{~J}_{1}$ & $\mathbf{J}_{2}$ & $\mathrm{~J}_{3}$ & $\mathrm{~J}_{0}$ \\
\hline 3 & $\mathbf{J}_{2}$ & $\mathbf{J}_{3}$ & $\mathbf{J}_{0}$ & $\mathrm{~J}_{1}$ \\
\hline 4 & $\mathrm{~J}_{3}$ & $\mathrm{~J}_{0}$ & $\mathrm{~J}_{1}$ & $\mathrm{~J}_{2}$ \\
\hline 5 & $\mathrm{~J}_{3}$ & $\mathbf{J}_{2}$ & $\mathrm{~J}_{1}$ & $\mathbf{J}_{0}$ \\
\hline 6 & $\mathrm{~J}_{0}$ & $\mathbf{J}_{3}$ & $\mathrm{~J}_{2}$ & $\mathrm{~J}_{1}$ \\
\hline 7 & $\mathrm{~J}_{1}$ & $\mathbf{J}_{0}$ & $\mathrm{~J}_{3}$ & $\mathbf{J}_{2}$ \\
\hline 8 & $\mathrm{~J}_{2}$ & $\mathrm{~J}_{1}$ & $\mathrm{~J}_{0}$ & $\mathrm{~J}_{3}$ \\
\hline 9 & $\mathrm{~J}_{0}$ & $\mathrm{~J}_{1}$ & $\mathrm{~J}_{2}$ & $\mathrm{~J}_{3}$ \\
\hline 10 & $\mathrm{~J}_{1}$ & $\mathbf{J}_{2}$ & $\mathrm{~J}_{3}$ & $\mathrm{~J}_{0}$ \\
\hline
\end{tabular}

Table 3: Initial population.

from the pool. The result shows that, standard deviation of each job ranges between $[0,1]$.

Using the above information a randomized job sequence is initialized with population size 10 . As we have considered 4 jobs here, it can have 24 numbers of different possible sequences. Table 3 contains a random selection of 10 sequences out of these. These sequences will be the initial input for the proposed algorithm and the resulted intermediate sequences will be the further inputs for different iterations and bee phases.

\subsubsection{Large-size data}

The other synthetic large size dataset with population size 10 is generated with 10 jobs and 9 machines are set with the following parameter setting. Here the processing time of jobs are set to $[0,10]$. The weights and due times

\begin{tabular}{|c|c|c|c|c|c|c|c|c|c|c|}
\hline & Job 0 & Job 1 & $2^{\text {Job }}$ & 3 Job & $4^{\text {Job }}$ & $\begin{array}{ll} & \text { Job } \\
5 & \end{array}$ & $6^{\text {Job }}$ & $\begin{array}{ll} & \text { Job } \\
7 & \end{array}$ & b $8^{\text {Jo }}$ & $9_{9}$ Job \\
\hline Machine 1 & $\mathrm{O}_{11}=10$ & $\mathrm{O}_{12}=5$ & $\mathrm{O}_{13}=8$ & $\mathrm{O}_{14}=5$ & $\mathrm{O}_{15}=1$ & $\mathrm{O}_{16}=7$ & $\mathrm{O}_{17}=2$ & $\mathrm{O}_{18}=0$ & $\mathrm{O}_{19}=9$ & $\mathrm{O}_{110}=3$ \\
\hline Machine 2 & $\mathrm{O}_{21}=3$ & $\mathrm{O}_{22}=4$ & $\mathrm{O}_{23}=5$ & $\mathrm{O}_{24}=8$ & $\mathrm{O}_{25}=3$ & $\mathrm{O}_{26}=6$ & $\mathrm{O}_{27}=2$ & $\mathrm{O}_{28}=5$ & $\mathrm{O}_{29}=7$ & $\mathrm{O}_{210}=4$ \\
\hline Machine 3 & $\mathrm{O}_{31}=5$ & $\mathrm{O}_{32}=3$ & $\mathrm{O}_{33}=0$ & $\mathrm{O}_{34}=3$ & $\mathrm{O}_{35}=5$ & $\mathrm{O}_{36}=9$ & $\mathrm{O}_{37}=0$ & $\mathrm{O}_{38}=0$ & $\mathrm{O}_{39}=2$ & $\mathrm{O}_{310}=3$ \\
\hline Machine 4 & $\mathrm{O}_{41}=4$ & $\mathrm{O}_{42}=2$ & $\mathrm{O}_{43}=4$ & $\mathrm{O}_{44}=7$ & $\mathrm{O}_{45}=2$ & $\mathrm{O}_{46}=3$ & $\mathrm{O}_{47}=4$ & $\mathrm{O}_{48}=9$ & $\mathrm{O}_{49}=0$ & $\mathrm{O}_{410}=3$ \\
\hline Machine 5 & $\mathrm{O}_{51}=1$ & $\mathrm{O}_{52}=2$ & $\mathrm{O}_{53}=1$ & $\mathrm{O}_{54}=5$ & $\mathrm{O}_{55}=4$ & $\mathrm{O}_{56}=7$ & $\mathrm{O}_{57}=2$ & $\mathrm{O}_{58}=3$ & $\mathrm{O}_{59}=4$ & $\mathrm{O}_{510}=6$ \\
\hline Machine 6 & $\mathrm{O}_{61}=7$ & $\mathrm{O}_{62}=3$ & $\mathrm{O}_{63}=2$ & $\mathrm{O}_{64}=5$ & $\mathrm{O}_{65}=3$ & $\mathrm{O}_{66}=6$ & $\mathrm{O}_{67}=9$ & $\mathrm{O}_{68}=4$ & $\mathrm{O}_{69}=4$ & $\mathrm{O}_{610}=2$ \\
\hline Machine 7 & $\mathrm{O}_{71}=3$ & $\mathrm{O}_{72}=0$ & $\mathrm{O}_{73}=2$ & $\mathrm{O}_{74}=0$ & $\mathrm{O}_{75}=5$ & $\mathrm{O}_{76}=5$ & $\mathrm{O}_{77}=5$ & $\mathrm{O}_{78}=4$ & $\mathrm{O}_{79}=2$ & $\mathrm{O}_{710}=2$ \\
\hline Machine 8 & $\mathrm{O}_{81}=8$ & $\mathrm{O}_{82}=4$ & $\mathrm{O}_{83}=1$ & $\mathrm{O}_{84}=0$ & $\mathrm{O}_{85}=5$ & $\mathrm{O}_{86}=9$ & $\mathrm{O}_{87}=4$ & $\mathrm{O}_{88}=5$ & $\mathrm{O}_{89}=4$ & $\mathrm{O}_{810}=6$ \\
\hline Machine 9 & $\mathrm{O}_{91}=2$ & $\mathrm{O}_{92}=4$ & $\mathrm{O}_{93}=1$ & $\mathrm{O}_{94}=10$ & $\mathrm{O}_{95}=8$ & $\mathrm{O}_{96}=3$ & $\mathrm{O}_{97}=4$ & $\mathrm{O}_{98}=5$ & $\mathrm{O}_{99}=4$ & $\mathrm{O}_{910}=7$ \\
\hline Due time & 80 & 42 & 75 & 85 & 95 & 60 & $\begin{array}{ll} & 10 \\
0 & \end{array}$ & 10 & 9 & 65 \\
\hline Weight & 2 & 3 & 4 & 6 & 10 & 1 & 4 & 5 & 7 & 9 \\
\hline
\end{tabular}

Table 4: Processing time of machine vs job task. 


\begin{tabular}{|c|c|c|c|}
\hline \multicolumn{1}{|l|}{ Jobs } & Minimum & Maximum & Standard deviation \\
\hline 1 & 1 & 10 & 2.81 \\
\hline 2 & 0 & 5 & 1.45 \\
\hline 3 & 0 & 8 & 2.40 \\
\hline 4 & 0 & 10 & 3.18 \\
\hline 5 & 1 & 8 & 1.94 \\
\hline 6 & 3 & 9 & 2.07 \\
\hline 7 & 0 & 9 & 2.40 \\
\hline 8 & 0 & 9 & 2.72 \\
\hline 9 & 0 & 9 & 2.53 \\
\hline 10 & 2 & 7 & 1.76 \\
\hline
\end{tabular}

Table 5: Statistics of the large-size dataset.

are initialized within $[1,10]$ and $[50,100]$ respectively. The destruction size has been assumed as 4 . The same required data as per the small sized dataset are also represented using different tabulations in the same sequence.

\section{Parameter setting}

(i)

$O_{j k}:[0-10]$

(ii) Weight (tardiness and earliness): $[1,10]$

(iii) Population size: 10

(iv) Destruction size: 4

As per the parameter setting, Table 4 is finalized with different processing times for individual jobs with respect to corresponding machines. It also assumes the due times and job weights. Job weights are basically the representative of their priorities.

Similar to the first dataset, we have also done a statistical analysis of the large-size dataset in Table 5.As per the minimum and maximum processing time of each job, the standard deviation of the jobs ranges between $[1,3]$.

Table 6 contains the initial population set consisting of 10 jobs. These jobs can be arranged in 10 ! number of possible ways and we have selected a random 10 out of it

\begin{tabular}{|c|c|c|c|c|c|c|c|c|c|c|}
\hline $\mathrm{P}$ & \multicolumn{10}{|c|}{ Job sequence } \\
\hline 1 & $\mathbf{J}_{0}$ & $\mathrm{~J}_{1}$ & $\mathrm{~J}_{2}$ & $\mathbf{J}_{3}$ & $\mathrm{~J}_{4}$ & $\mathrm{~J}_{5}$ & $\mathrm{~J}_{6}$ & $\mathrm{~J}_{7}$ & $\mathrm{~J}_{8}$ & $\mathrm{~J}_{9}$ \\
\hline 2 & $\mathrm{~J}_{1}$ & $\mathrm{~J}_{2}$ & $\mathrm{~J}_{3}$ & $\mathrm{~J}_{4}$ & $\mathrm{~J}_{5}$ & $\mathrm{~J}_{6}$ & $\mathbf{J}_{7}$ & $\mathrm{~J}_{8}$ & $\mathrm{~J}_{9}$ & $\mathrm{~J}_{0}$ \\
\hline 3 & $\mathbf{J}_{2}$ & $\mathrm{~J}_{3}$ & $\mathrm{~J}_{4}$ & $\mathrm{~J}_{5}$ & $\mathrm{~J}_{6}$ & $\mathrm{~J}_{7}$ & $\mathbf{J}_{8}$ & $\mathrm{~J}_{9}$ & $\mathrm{~J}_{0}$ & $\mathrm{~J}_{1}$ \\
\hline 4 & $\mathbf{J}_{3}$ & $\mathrm{~J}_{4}$ & $\mathrm{~J}_{5}$ & $\mathrm{~J}_{6}$ & $\mathrm{~J}_{7}$ & $\mathbf{J}_{8}$ & $\mathrm{~J}_{9}$ & $\mathrm{~J}_{0}$ & $\mathrm{~J}_{1}$ & $\mathrm{~J}_{2}$ \\
\hline 5 & $\mathrm{~J}_{4}$ & $\mathrm{~J}_{5}$ & $\mathrm{~J}_{6}$ & $\mathrm{~J}_{7}$ & $\mathrm{~J}_{8}$ & $\mathbf{J}_{9}$ & $\mathbf{J}_{0}$ & $\mathrm{~J}_{1}$ & $\mathrm{~J}_{2}$ & $\mathrm{~J}_{3}$ \\
\hline 6 & $\mathrm{~J}_{5}$ & $\mathrm{~J}_{6}$ & $\mathrm{~J}_{7}$ & $\mathbf{J}_{8}$ & $\mathbf{J}_{9}$ & $\mathbf{J}_{0}$ & $\mathrm{~J}_{1}$ & $\mathrm{~J}_{2}$ & $\mathrm{~J}_{3}$ & $\mathrm{~J}_{4}$ \\
\hline 7 & $\mathrm{~J}_{6}$ & $\mathrm{~J}_{7}$ & $\mathbf{J}_{8}$ & $\mathbf{J}_{9}$ & $\mathrm{~J}_{0}$ & $\mathrm{~J}_{1}$ & $\mathbf{J}_{2}$ & $\mathrm{~J}_{3}$ & $\mathrm{~J}_{4}$ & $\mathrm{~J}_{5}$ \\
\hline 8 & $\mathrm{~J}_{7}$ & $\mathrm{~J}_{8}$ & $\mathrm{~J}_{9}$ & $\mathbf{J}_{0}$ & $\mathrm{~J}_{1}$ & $\mathbf{J}_{2}$ & $\mathbf{J}_{3}$ & $\mathrm{~J}_{4}$ & $\mathrm{~J}_{5}$ & $\mathrm{~J}_{6}$ \\
\hline 9 & $\mathbf{J}_{8}$ & $\mathrm{~J}_{9}$ & $\mathrm{~J}_{0}$ & $\mathrm{~J}_{1}$ & $\mathrm{~J}_{2}$ & $\mathrm{~J}_{3}$ & $\mathrm{~J}_{4}$ & $\mathrm{~J}_{5}$ & $\mathrm{~J}_{6}$ & $\mathrm{~J}_{7}$ \\
\hline 10 & $\mathbf{J}_{9}$ & $\mathbf{J}_{0}$ & $\mathrm{~J}_{1}$ & $\mathrm{~J} 2$ & $\mathrm{~J}_{3}$ & $\mathrm{~J}_{4}$ & $\mathrm{~J}_{5}$ & $\mathrm{~J}_{6}$ & $\mathrm{~J}_{7}$ & $\mathbf{J}_{8}$ \\
\hline
\end{tabular}

Table 6: Initial population. as the initial input. As compared to the small-sized dataset there is a very less chance of repeating the same sequences as the intermediate result sequences, due the application of different tuning operators (insert/swap/construct-destruct).

\subsection{Numerical results and analysis}

Using the above specified inputs the results are tabulated separately for each algorithm. First, the results of DABC are represented and then that of MOABC. Firstly the results are tabulated then are reflected into corresponding graphical representations through the help of various figures where ' $\mathrm{X}$ ' and ' $\mathrm{Y}$ ' dimensions represents the 'performance score' versus 'job sequences' respectively. Each unit of ' $\mathrm{X}$ ' and ' $\mathrm{Y}$ ' dimension in the small-size dataset counts as 5 and 1 respectively, similarly it counts as 20 and 1 for the large- size dataset for the same dimensional sequence.

\subsubsection{Results of DABC Algorithm}

The tabulated results include the performance of DABC algorithms for individual cases with two specified inputs. Table 7-9 represents the final job sequences for small dataset corresponding to TCT, MWT and MWE and table 10-12 includes the results for the other input dataset. Table 7 and 10 includes the results of DABC-I algorithm with swap () and insert () operation having random perturbation values 2 or 3 . Table 8 and 11 shows the results of DABC-II, that include another operation construct-destruct () additional to the operations of DABC-I. Only construct-destruct is used in DABC-III and the results are tabulated in Table 9 and 12 .

\subsubsection{Small-size dataset}

Table 7 contains the resulted TCT, MWT, MWE of the small-sized dataset for DABC-I. As mentioned, DABC-I uses the swap () and insert () algorithms to update the solution vectors. The result includes the completion time of every job in different sequences and TCT of each job sequence is equal to the completion time of the last job of the individual sequence. According to the initialized weight and due time the respective MWT and MWE has been calculated.

The graphical representation of Table 7 has been shown in Figure 10. Each job sequences have been represented individually with its corresponding TCT, MWE, and MWT scores.

The results of DABC-II is tabulated in Table 8.Based on the completion time, weight and due date of individual jobs the corresponding TCT, MWT, and MWE values are summarized and presented here. To update the job sequences here all the local search methods (insert/swap/construction and destruction) have been applied randomly. 


\begin{tabular}{|c|c|c|c|c|c|c|c|}
\hline \multirow{3}{*}{$\begin{array}{l}P \\
\\
1\end{array}$} & \multicolumn{4}{|c|}{$\begin{array}{l}\text { Final job sequence \& } \\
\text { completion time }\end{array}$} & \multirow{3}{*}{$\begin{array}{l}\mathrm{TC} \\
\mathrm{T} \\
19\end{array}$} & \multirow{3}{*}{$\begin{array}{l}\text { MW } \\
\text { T } \\
0.72\end{array}$} & \multirow{3}{*}{$\begin{array}{l}\text { MWE } \\
5.54\end{array}$} \\
\hline & $\mathrm{J}_{3}$ & $\mathrm{~J}_{1}$ & $\mathrm{~J}_{0}$ & $\mathrm{~J}_{2}$ & & & \\
\hline & 9 & 11 & 16 & 19 & & & \\
\hline \multirow[t]{2}{*}{2} & $\mathrm{~J}_{3}$ & $\mathrm{~J}_{1}$ & $\mathrm{~J}_{2}$ & $\mathrm{~J}_{0}$ & \multirow[t]{2}{*}{20} & \multirow[t]{2}{*}{0.9} & \multirow[t]{2}{*}{5.9} \\
\hline & 9 & 11 & 15 & 20 & & & \\
\hline \multirow[t]{2}{*}{3} & $\mathrm{~J}_{0}$ & $\mathrm{~J}_{1}$ & $\mathrm{~J}_{3}$ & $\mathrm{~J}_{2}$ & \multirow[t]{2}{*}{21} & \multirow[t]{2}{*}{2.0} & \multirow[t]{2}{*}{4.36} \\
\hline & 12 & 14 & 18 & 21 & & & \\
\hline \multirow[t]{2}{*}{4} & $\mathrm{~J}_{1}$ & $\mathrm{~J}_{0}$ & $\mathrm{~J}_{2}$ & $\mathrm{~J}_{3}$ & \multirow[t]{2}{*}{21} & \multirow[t]{2}{*}{1.3} & \multirow[t]{2}{*}{5.6} \\
\hline & 5 & 13 & 17 & 21 & & & \\
\hline \multirow[t]{2}{*}{5} & $\mathrm{~J}_{1}$ & $\mathrm{~J}_{2}$ & $\mathrm{~J}_{0}$ & $\mathrm{~J}_{3}$ & \multirow[t]{2}{*}{22} & \multirow[t]{2}{*}{1.54} & \multirow[t]{2}{*}{5.27} \\
\hline & 5 & 13 & 18 & 22 & & & \\
\hline \multirow[t]{2}{*}{6} & $\mathrm{~J}_{1}$ & $\mathrm{~J}_{2}$ & $\mathrm{~J}_{3}$ & $\mathrm{~J}_{0}$ & \multirow[t]{2}{*}{22} & \multirow[t]{2}{*}{1.54} & \multirow[t]{2}{*}{5.63} \\
\hline & 5 & 13 & 17 & 22 & & & \\
\hline \multirow[t]{2}{*}{7} & $\mathrm{~J}_{2}$ & $\mathrm{~J}_{1}$ & $\mathrm{~J}_{0}$ & $\mathrm{~J}_{3}$ & \multirow[t]{2}{*}{23} & \multirow[t]{2}{*}{2.36} & \multirow[t]{2}{*}{4.0} \\
\hline & 12 & 14 & 19 & 23 & & & \\
\hline \multirow[t]{2}{*}{8} & $\mathrm{~J}_{0}$ & $\mathrm{~J}_{3}$ & $\mathrm{~J}_{2}$ & $\mathrm{~J}_{1}$ & \multirow[t]{2}{*}{21} & \multirow[t]{2}{*}{2.54} & \multirow[t]{2}{*}{4.0} \\
\hline & 12 & 16 & 19 & 21 & & & \\
\hline \multirow[t]{2}{*}{9} & $\mathrm{~J}_{0}$ & $\mathrm{~J}_{3}$ & $\mathrm{~J}_{1}$ & $\mathrm{~J}_{2}$ & \multirow[t]{2}{*}{21} & 2.54 & 4.36 \\
\hline & 12 & 16 & 18 & 21 & & & \\
\hline 10 & $\mathrm{~J}_{2}$ & $\mathrm{~J}_{3}$ & $\mathrm{~J}_{1}$ & $\mathrm{~J}_{0}$ & 23 & 2.9 & 4.36 \\
\hline & - & 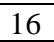 & 18 & 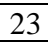 & & & \\
\hline
\end{tabular}

Table 7: Results of DABC-I.

\begin{tabular}{|c|c|c|c|c|c|c|c|}
\hline Population & \multicolumn{4}{|c|}{$\begin{array}{c}\text { Final job } \\
\text { sequence \& } \\
\text { completion time }\end{array}$} & TCT & MWT & MWE \\
\hline \multirow[t]{2}{*}{1} & $\mathrm{~J}_{1}$ & $\mathrm{~J}_{3}$ & $\mathrm{~J}_{0}$ & $\mathrm{~J}_{2}$ & \multirow[t]{2}{*}{19} & \multirow[t]{2}{*}{0.72} & \multirow[t]{2}{*}{6.9} \\
\hline & 5 & 10 & 15 & 19 & & & \\
\hline \multirow[t]{2}{*}{2} & $\mathrm{~J}_{3}$ & $\mathrm{~J}_{0}$ & $\mathrm{~J}_{1}$ & $\mathrm{~J}_{2}$ & \multirow[t]{2}{*}{19} & \multirow[t]{2}{*}{1.27} & \multirow[t]{2}{*}{5.27} \\
\hline & 9 & 14 & 16 & 19 & & & \\
\hline \multirow[t]{2}{*}{3} & $\mathrm{~J}_{1}$ & $\mathrm{~J}_{3}$ & $\mathrm{~J}_{2}$ & $\mathrm{~J}_{0}$ & \multirow[t]{2}{*}{20} & \multirow[t]{2}{*}{0.90} & \multirow[t]{2}{*}{6.9} \\
\hline & 5 & 10 & 15 & 20 & & & \\
\hline \multirow[t]{2}{*}{4} & $\mathrm{~J}_{3}$ & $\mathrm{~J}_{2}$ & $\mathrm{~J}_{1}$ & $\mathrm{~J}_{0}$ & \multirow[t]{2}{*}{21} & \multirow[t]{2}{*}{1.63} & \multirow[t]{2}{*}{5.27} \\
\hline & 9 & 14 & 16 & 21 & & & \\
\hline \multirow[t]{2}{*}{5} & $\mathrm{~J}_{3}$ & $\mathrm{~J}_{2}$ & $\mathrm{~J}_{1}$ & $\mathrm{~J}_{0}$ & \multirow[t]{2}{*}{21} & \multirow[t]{2}{*}{1.63} & \multirow[t]{2}{*}{5.27} \\
\hline & 9 & 14 & 16 & 21 & & & \\
\hline \multirow[t]{2}{*}{6} & $\mathrm{~J}_{3}$ & $\mathrm{~J}_{2}$ & $\mathrm{~J}_{1}$ & $\mathrm{~J}_{0}$ & \multirow[t]{2}{*}{21} & \multirow[t]{2}{*}{1.63} & \multirow[t]{2}{*}{5.27} \\
\hline & 9 & 14 & 16 & 21 & & & \\
\hline \multirow[t]{2}{*}{7} & $\mathrm{~J}_{3}$ & $\mathrm{~J}_{2}$ & $\mathrm{~J}_{0}$ & $\mathrm{~J}_{1}$ & \multirow[t]{2}{*}{21} & \multirow[t]{2}{*}{1.63} & \multirow[t]{2}{*}{4.18} \\
\hline & 9 & 14 & 19 & 21 & & & \\
\hline \multirow[t]{2}{*}{8} & $\mathrm{~J}_{0}$ & $\mathrm{~J}_{2}$ & $\mathrm{~J}_{3}$ & $\mathrm{~J}_{1}$ & \multirow[t]{2}{*}{22} & \multirow[t]{2}{*}{2.72} & \multirow[t]{2}{*}{3.63} \\
\hline & 12 & 16 & 20 & 22 & & & \\
\hline \multirow[t]{2}{*}{9} & $\mathrm{~J}_{0}$ & $\mathrm{~J}_{2}$ & $\mathrm{~J}_{3}$ & $\mathrm{~J}_{1}$ & \multirow[t]{2}{*}{22} & 2.72 & 3.63 \\
\hline & 12 & 16 & 20 & 22 & & & \\
\hline 10 & $\mathrm{~J}_{2}$ & $\mathrm{~J}_{0}$ & $\mathrm{~J}_{1}$ & $\mathrm{~J}_{3}$ & 23 & 3.18 & 4.0 \\
\hline & 12 & 17 & 19 & 23 & & & \\
\hline
\end{tabular}

Table 8: Results of DABC-II.

The tabulated results of DABC-II are graphically represented in Figure 11. Like DABC-I, most of the cases have more earliness penalty than the tardiness penalty. While adopting selection of average number of solution sequences from each objective, we found some of the repeating sequences. These have to be treated as one ultimately. Hence, the total numbers of nondominated sequences are 7 in number but we have represented all repeated sequences also.

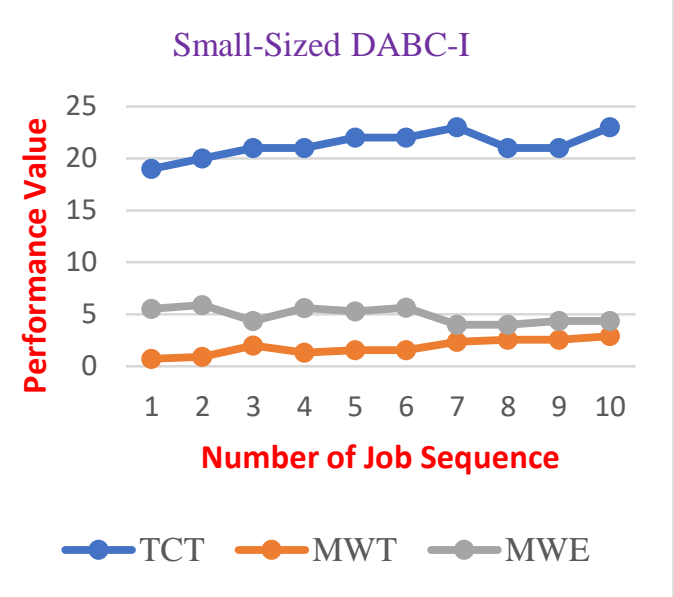

Figure 10 Graphical representation of DABC-I.

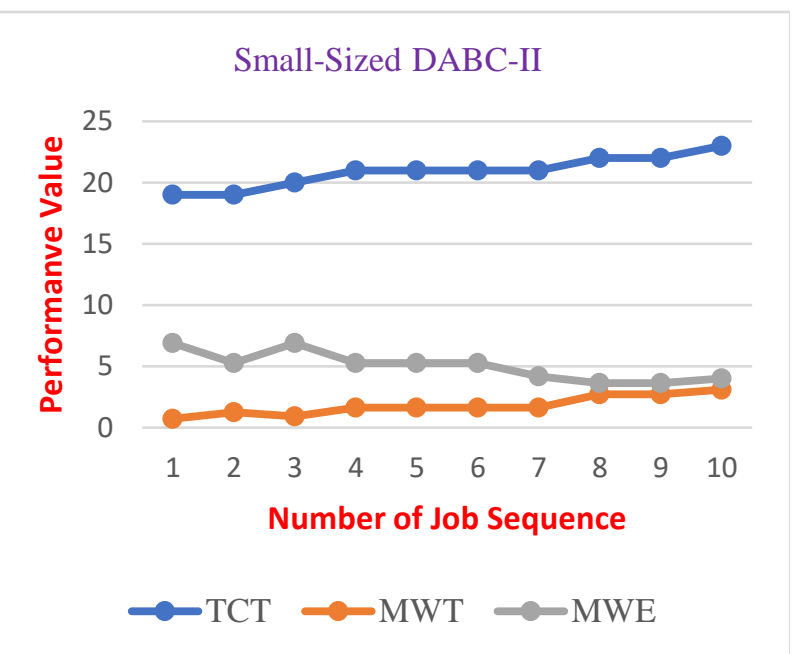

Figure 11: Graphical representation of DABC-II.

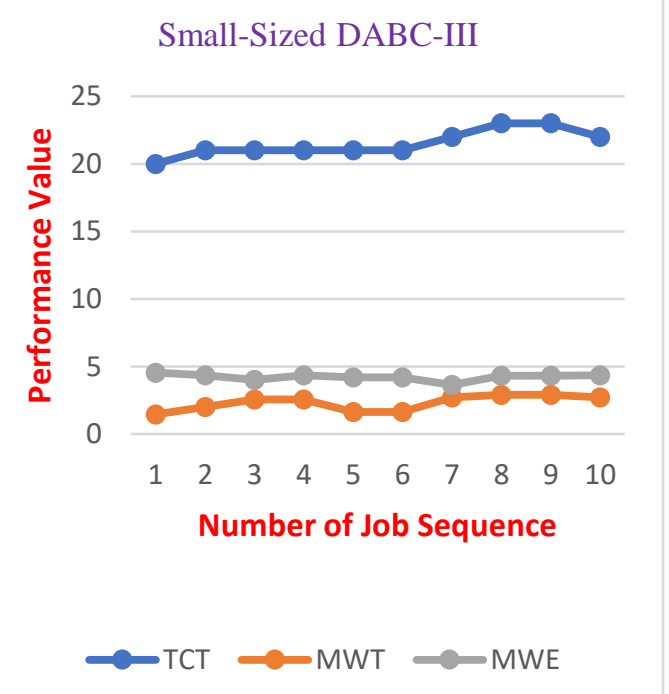

Figure 12: Graphical representation of DABC-III.

The results of DABC-III have been listed in Table 9. The three objective functions are evaluated with a recursive set of sequences and the fitness values are summarized. DABC-III explicitly uses destructconstruct for perturbing the solution sets. 


\begin{tabular}{|c|c|c|c|c|c|c|c|}
\hline$P$ & \multicolumn{4}{|c|}{\begin{tabular}{l}
\multicolumn{1}{c}{ Final job } \\
sequence \& \\
completion time
\end{tabular}} & $\begin{array}{ll} & \mathrm{TC} \\
\mathrm{T} & \end{array}$ & $\mathrm{WT}^{\mathrm{M}}$ & $\mathrm{WE}^{\mathrm{M}}$ \\
\hline \multirow[t]{2}{*}{1} & $\mathrm{~J}_{3}$ & $\mathrm{~J}_{0}$ & $\mathrm{~J}_{2}$ & $\mathrm{~J}_{1}$ & \multirow[t]{2}{*}{20} & \multirow[t]{2}{*}{1.45} & \multirow[t]{2}{*}{4.54} \\
\hline & 9 & 14 & 18 & 20 & & & \\
\hline \multirow[t]{2}{*}{2} & $\mathrm{~J}_{0}$ & $\mathrm{~J}_{1}$ & $\mathrm{~J}_{3}$ & $\mathrm{~J}_{2}$ & \multirow[t]{2}{*}{21} & \multirow[t]{2}{*}{2.0} & \multirow[t]{2}{*}{4.36} \\
\hline & 12 & 14 & 18 & 21 & & & \\
\hline \multirow[t]{2}{*}{3} & $\mathrm{~J}_{0}$ & $\mathrm{~J}_{3}$ & $\mathrm{~J}_{2}$ & $\mathrm{~J}_{1}$ & \multirow[t]{2}{*}{21} & \multirow[t]{2}{*}{2.54} & \multirow[t]{2}{*}{4.0} \\
\hline & 12 & 16 & 19 & 21 & & & \\
\hline \multirow[t]{2}{*}{4} & $\mathrm{~J}_{0}$ & $\mathrm{~J}_{3}$ & $\mathrm{~J}_{1}$ & $\mathrm{~J}_{2}$ & \multirow[t]{2}{*}{21} & \multirow[t]{2}{*}{2.54} & \multirow[t]{2}{*}{4.36} \\
\hline & 12 & 16 & 18 & 21 & & & \\
\hline \multirow[t]{2}{*}{5} & $\mathrm{~J}_{3}$ & $\mathrm{~J}_{2}$ & $\mathrm{~J}_{0}$ & $\mathrm{~J}_{1}$ & \multirow[t]{2}{*}{21} & \multirow[t]{2}{*}{1.63} & \multirow[t]{2}{*}{4.18} \\
\hline & 9 & 14 & 19 & 21 & & & \\
\hline \multirow[t]{2}{*}{6} & $\mathrm{~J}_{3}$ & $\mathrm{~J}_{2}$ & $\mathrm{~J}_{0}$ & $\mathrm{~J}_{1}$ & \multirow[t]{2}{*}{21} & \multirow[t]{2}{*}{1.63} & \multirow[t]{2}{*}{4.18} \\
\hline & 9 & 14 & 19 & 21 & & & \\
\hline \multirow[t]{2}{*}{7} & $\mathrm{~J}_{0}$ & $\mathrm{~J}_{2}$ & $\mathrm{~J}_{3}$ & $\mathrm{~J}_{1}$ & \multirow[t]{2}{*}{22} & \multirow[t]{2}{*}{2.72} & \multirow[t]{2}{*}{3.63} \\
\hline & 12 & 16 & 20 & 22 & & & \\
\hline \multirow[t]{2}{*}{8} & $\mathrm{~J}_{2}$ & $\mathrm{~J}_{3}$ & $\mathrm{~J}_{1}$ & $\mathrm{~J}_{0}$ & \multirow[t]{2}{*}{23} & \multirow[t]{2}{*}{2.9} & \multirow[t]{2}{*}{4.3} \\
\hline & 12 & 16 & 18 & 23 & & & \\
\hline \multirow[t]{2}{*}{9} & $\mathrm{~J}_{2}$ & $\mathrm{~J}_{3}$ & $\mathrm{~J}_{1}$ & $\mathrm{~J}_{0}$ & \multirow[t]{2}{*}{23} & 2.9 & 4.3 \\
\hline & 12 & 16 & 18 & 23 & & & \\
\hline 1 & $\mathrm{~J}_{0}$ & $\mathrm{~J}_{2}$ & $\mathrm{~J}_{1}$ & $\mathrm{~J}_{3}$ & 22 & 2.72 & 4.36 \\
\hline 0 & 12 & 16 & 18 & 22 & & & \\
\hline
\end{tabular}

Table 9: Results of DABC-III.

Table 9 results are graphically represented in Figure 12 showing a clear-cut demarcation of TCT, MWE, and MWT for 10 different sequences. Apart from TCT, most of the non-dominated sequences have earliness penalty is more than tardiness penalty.

\subsubsection{Large-size dataset}

Table 10 stores the results of DABC-I for the large-sized dataset. Along with every sequence, the completion time of individual jobs are listed leading to the TCT score of that sequence. Out of 10 random sequences of 10 different jobs, 8 sequences are having greater MWE score than MWT.

Table 10 is graphically represented in Figure 13, showing the ratio of MWE score, MWT score, and TMT score of individual job sequence. Except sequence 10 and 9, other sequences are having more MWE score than MWT score.

Results of DABC-II for the second input are stored in Table 11. The results also show similar efficiency as that before. Here also the earliness cost is more in many sequences.

Figure 14 represents Table 11 . We can obtain the better sequences having minimum TCT, MWT, and MWE. As discussed, DABC-II uses all the local search methods to improve pre existing solutions.

DABC-III results for the large-sized input are tabulated in Table 12. It shows construct-destruct () has similar efficiency to search good solutions from the search space. But, out of all local search algorithms this one is having maximum algorithmic complexity.

Figure 15 represents DABC-III, pictorially showing the fitness value of different resulted sequences.

As discussed above the result tables and corresponding graphs have been represented below.

\begin{tabular}{|c|c|c|c|c|c|c|c|c|c|c|c|c|c|}
\hline $\mathrm{P}$ & \multicolumn{10}{|c|}{ Final job sequence \& completion time } & TCT & MWT & MWE \\
\hline \multirow[t]{2}{*}{1} & $\mathbf{J}_{7}$ & $\mathrm{~J}_{4}$ & $\mathrm{~J}_{3}$ & $\mathrm{~J}_{5}$ & $\mathrm{~J}_{6}$ & $\mathbf{J}_{8}$ & $\mathrm{~J}_{9}$ & $\mathbf{J}_{0}$ & $\mathrm{~J}_{1}$ & $\mathrm{~J}_{2}$ & \multirow[t]{2}{*}{92} & \multirow[t]{2}{*}{5.21} & \multirow[t]{2}{*}{14.43} \\
\hline & 35 & 43 & 53 & 64 & 69 & 73 & 82 & 85 & 91 & 92 & & & \\
\hline \multirow[t]{2}{*}{2} & $\mathrm{~J}_{7}$ & $\mathrm{~J}_{2}$ & $\mathrm{~J}_{4}$ & $\mathrm{~J}_{5}$ & $\mathrm{~J}_{6}$ & $\mathrm{~J}_{3}$ & $\mathrm{~J}_{8}$ & $\mathbf{J}_{9}$ & $\mathrm{~J}_{0}$ & $\mathrm{~J}_{1}$ & \multirow[t]{2}{*}{96} & \multirow[t]{2}{*}{6.11} & \multirow[t]{2}{*}{14.6} \\
\hline & 35 & 36 & 48 & 64 & 69 & 79 & 83 & 90 & 92 & 96 & & & \\
\hline \multirow[t]{2}{*}{3} & $\mathrm{~J}_{7}$ & $\mathrm{~J}_{5}$ & $\mathrm{~J}_{8}$ & $\mathrm{~J}_{4}$ & $\mathbf{J}_{9}$ & $\mathbf{J}_{0}$ & $\mathrm{~J}_{1}$ & $\mathbf{J}_{2}$ & $\mathrm{~J}_{3}$ & $\mathrm{~J}_{6}$ & \multirow[t]{2}{*}{98} & \multirow[t]{2}{*}{7.49} & \multirow[t]{2}{*}{11.94} \\
\hline & 35 & 55 & 60 & 69 & 76 & 78 & 83 & 84 & 94 & 98 & & & \\
\hline \multirow[t]{2}{*}{4} & $\mathrm{~J}_{0}$ & $\mathrm{~J}_{1}$ & $\mathrm{~J}_{6}$ & $\mathrm{~J}_{3}$ & $\mathrm{~J}_{4}$ & $\mathrm{~J}_{5}$ & $\mathrm{~J}_{2}$ & $\mathbf{J}_{7}$ & $\mathrm{~J}_{8}$ & $\mathrm{~J}_{9}$ & \multirow[t]{2}{*}{100} & \multirow[t]{2}{*}{7.25} & \multirow[t]{2}{*}{12.84} \\
\hline & 43 & 49 & 55 & 65 & 73 & 80 & 81 & 88 & 92 & 100 & & & \\
\hline \multirow[t]{2}{*}{5} & $\mathrm{~J}_{1}$ & $\mathrm{~J}_{2}$ & $\mathbf{J}_{3}$ & $\mathrm{~J}_{4}$ & $\mathbf{J}_{8}$ & $\mathrm{~J}_{6}$ & $\mathbf{J}_{7}$ & $\mathrm{~J}_{5}$ & $\mathrm{~J}_{9}$ & $\mathrm{~J}_{0}$ & \multirow[t]{2}{*}{104} & \multirow[t]{2}{*}{8.68} & \multirow[t]{2}{*}{14.0} \\
\hline & 27 & 29 & 56 & 67 & 71 & 75 & 81 & 91 & 101 & 104 & & & \\
\hline \multirow[t]{2}{*}{6} & $\mathbf{J}_{9}$ & $\mathbf{J}_{7}$ & $\mathbf{J}_{0}$ & $\mathrm{~J}_{1}$ & $\mathbf{J}_{2}$ & $\mathbf{J}_{8}$ & $\mathbf{J}_{3}$ & $\mathrm{~J}_{4}$ & $\mathrm{~J}_{5}$ & $\mathrm{~J}_{6}$ & \multirow[t]{2}{*}{106} & \multirow[t]{2}{*}{8.84} & \multirow[t]{2}{*}{17.8} \\
\hline & 36 & 43 & 49 & 55 & 56 & 62 & 80 & 91 & 101 & 106 & & & \\
\hline \multirow[t]{2}{*}{7} & $\mathrm{~J}_{0}$ & $\mathrm{~J}_{1}$ & $\mathbf{J}_{2}$ & $\mathrm{~J}_{9}$ & $\mathrm{~J}_{3}$ & $\mathrm{~J}_{4}$ & $\mathrm{~J}_{5}$ & $\mathrm{~J}_{6}$ & $\mathbf{J}_{7}$ & $\mathrm{~J}_{8}$ & \multirow[t]{2}{*}{106} & \multirow[t]{2}{*}{9.7} & \multirow[t]{2}{*}{12.52} \\
\hline & 43 & 49 & 50 & 61 & 71 & 81 & 91 & 96 & 102 & 106 & & & \\
\hline \multirow[t]{2}{*}{8} & $\mathrm{~J}_{5}$ & $\mathrm{~J}_{6}$ & $\mathrm{~J}_{9}$ & $\mathrm{~J}_{8}$ & $\mathrm{~J}_{0}$ & $\mathbf{J}_{7}$ & $\mathrm{~J}_{1}$ & $\mathrm{~J}_{2}$ & $\mathrm{~J}_{3}$ & $\mathrm{~J}_{4}$ & \multirow[t]{2}{*}{107} & \multirow[t]{2}{*}{10.17} & 9.0 \\
\hline & 55 & 60 & 69 & 73 & 76 & 85 & 88 & 89 & 99 & 107 & & & \\
\hline 9 & $\mathrm{~J}_{1}$ & $\mathrm{~J}_{2}$ & $\mathbf{J}_{3}$ & $\mathrm{~J}_{5}$ & $\mathrm{~J}_{4}$ & $\mathrm{~J}_{6}$ & $\mathbf{J}_{7}$ & $\mathbf{J}_{8}$ & $\mathrm{~J}_{9}$ & $\mathrm{~J}_{0}$ & 106 & 9.7 & 9.11 \\
\hline & 27 & 29 & 56 & 74 & 84 & 88 & 93 & 97 & 104 & 106 & & & \\
\hline 10 & $\mathrm{~J}_{8}$ & $\mathbf{J}_{2}$ & $\mathbf{J}_{0}$ & $\mathbf{J}_{3}$ & $\mathrm{~J}_{4}$ & $\mathrm{~J}_{5}$ & $\mathbf{J}_{6}$ & $\mathbf{J}_{7}$ & $\mathbf{J}_{9}$ & $\mathrm{~J}_{1}$ & 107 & 9.66 & 11.9 \\
\hline & 36 & 37 & 55 & 65 & 74 & 84 & 89 & 95 & 103 & 107 & & & \\
\hline
\end{tabular}

Table 10: Results of DABC-I. 


\begin{tabular}{|c|c|c|c|c|c|c|c|c|c|c|c|c|c|}
\hline $\mathrm{P}$ & \multicolumn{10}{|c|}{ Final job sequence \& completion time } & TCT & MWT & MWE \\
\hline \multirow[t]{2}{*}{1} & $\mathrm{~J}_{9}$ & $\mathrm{~J}_{0}$ & $\mathrm{~J}_{1}$ & $\mathrm{~J}_{7}$ & $\mathrm{~J}_{3}$ & $\mathrm{~J}_{4}$ & $\mathrm{~J}_{5}$ & $\mathrm{~J}_{6}$ & $\mathrm{~J}_{8}$ & $\mathrm{~J}_{2}$ & \multirow[t]{2}{*}{94} & \multirow[t]{2}{*}{6.07} & \multirow[t]{2}{*}{14.82} \\
\hline & 36 & 46 & 52 & 58 & 68 & 76 & 84 & 89 & 93 & 94 & & & \\
\hline \multirow[t]{2}{*}{2} & $\mathbf{J}_{7}$ & $\mathrm{~J}_{8}$ & $\mathrm{~J}_{9}$ & $\mathrm{~J}_{4}$ & $\mathrm{~J}_{1}$ & $\mathrm{~J}_{0}$ & $\mathbf{J}_{2}$ & $\mathrm{~J}_{3}$ & $\mathrm{~J}_{6}$ & $\mathrm{~J}_{5}$ & \multirow[t]{2}{*}{95} & \multirow[t]{2}{*}{5.3} & \multirow[t]{2}{*}{20.49} \\
\hline & 35 & 39 & 49 & 57 & 61 & 63 & 64 & 74 & 85 & 95 & & & \\
\hline \multirow[t]{2}{*}{3} & $\mathrm{~J}_{6}$ & $\mathrm{~J}_{3}$ & $\mathrm{~J}_{4}$ & $\mathrm{~J}_{5}$ & $\mathrm{~J}_{7}$ & $\mathrm{~J}_{2}$ & $\mathbf{J}_{8}$ & $\mathrm{~J}_{9}$ & $\mathbf{J}_{0}$ & $\mathrm{~J}_{1}$ & \multirow[t]{2}{*}{95} & \multirow[t]{2}{*}{5.74} & \multirow[t]{2}{*}{13.64} \\
\hline & 32 & 45 & 56 & 66 & 73 & 74 & 78 & 86 & 89 & 95 & & & \\
\hline \multirow[t]{2}{*}{4} & $\mathrm{~J}_{3}$ & $\mathrm{~J}_{4}$ & $\mathrm{~J}_{8}$ & $\mathrm{~J}_{6}$ & $\mathrm{~J}_{7}$ & $\mathrm{~J}_{0}$ & $\mathbf{J}_{9}$ & $\mathrm{~J}_{5}$ & $\mathrm{~J}_{1}$ & $\mathbf{J}_{2}$ & \multirow[t]{2}{*}{95} & \multirow[t]{2}{*}{6.8} & \multirow[t]{2}{*}{13.6} \\
\hline & 43 & 54 & 58 & 62 & 68 & 73 & 84 & 89 & 94 & 95 & & & \\
\hline \multirow[t]{2}{*}{5} & $\mathrm{~J}_{6}$ & $\mathrm{~J}_{2}$ & $\mathrm{~J}_{3}$ & $\mathrm{~J}_{4}$ & $\mathrm{~J}_{5}$ & $\mathrm{~J}_{8}$ & $\mathbf{J}_{7}$ & $\mathrm{~J}_{1}$ & $\mathrm{~J}_{9}$ & $\mathrm{~J}_{0}$ & \multirow[t]{2}{*}{100} & \multirow[t]{2}{*}{7.5} & \multirow[t]{2}{*}{13.47} \\
\hline & 32 & 33 & 53 & 64 & 74 & 79 & 85 & 89 & 97 & 100 & & & \\
\hline \multirow[t]{2}{*}{6} & $\mathrm{~J}_{8}$ & $\mathrm{~J}_{9}$ & $\mathrm{~J}_{0}$ & $\mathrm{~J}_{2}$ & $\mathbf{J}_{7}$ & $\mathrm{~J}_{1}$ & $\mathrm{~J}_{3}$ & $\mathrm{~J}_{4}$ & $\mathrm{~J}_{5}$ & $\mathrm{~J}_{6}$ & \multirow[t]{2}{*}{109} & \multirow[t]{2}{*}{7.78} & \multirow[t]{2}{*}{15.82} \\
\hline & 36 & 49 & 54 & 55 & 66 & 70 & 80 & 88 & 96 & 109 & & & \\
\hline \multirow[t]{2}{*}{7} & $\mathrm{~J}_{8}$ & $\mathrm{~J}_{4}$ & $\mathrm{~J}_{0}$ & $\mathrm{~J}_{5}$ & $\mathrm{~J}_{6}$ & $\mathbf{J}_{7}$ & $\mathbf{J}_{9}$ & $\mathrm{~J}_{1}$ & $\mathbf{J}_{2}$ & $\mathrm{~J}_{3}$ & \multirow[t]{2}{*}{105} & \multirow[t]{2}{*}{8.7} & \multirow[t]{2}{*}{10.6} \\
\hline & 36 & 51 & 54 & 71 & 76 & 82 & 90 & 94 & 95 & 105 & & & \\
\hline \multirow[t]{2}{*}{8} & $\mathrm{~J}_{5}$ & $\mathrm{~J}_{6}$ & $\mathrm{~J}_{7}$ & $\mathrm{~J}_{8}$ & $\mathrm{~J}_{9}$ & $\mathrm{~J}_{0}$ & $\mathrm{~J}_{3}$ & $\mathrm{~J}_{2}$ & $\mathrm{~J}_{1}$ & $\mathrm{~J}_{4}$ & \multirow[t]{2}{*}{104} & \multirow[t]{2}{*}{9.17} & 8.76 \\
\hline & 55 & 60 & 66 & 70 & 78 & 81 & 91 & 92 & 96 & 104 & & & \\
\hline 9 & $\mathrm{~J}_{5}$ & $\mathrm{~J}_{2}$ & $\mathrm{~J}_{6}$ & $\mathrm{~J}_{0}$ & $\mathrm{~J}_{7}$ & $\mathbf{J}_{8}$ & $\mathbf{J}_{9}$ & $\mathrm{~J}_{1}$ & $\mathrm{~J}_{3}$ & $\mathrm{~J} 4$ & 111 & 11.13 & 9.45 \\
\hline & 55 & 56 & 62 & 69 & 77 & 81 & 89 & 93 & 103 & 111 & & & \\
\hline 10 & $\mathrm{~J}_{8}$ & $\mathrm{~J}_{2}$ & $\mathrm{~J}_{0}$ & $\mathrm{~J}_{3}$ & $\mathrm{~J}_{4}$ & $\mathrm{~J}_{5}$ & $\mathrm{~J}_{6}$ & $\mathrm{~J}_{7}$ & $\mathrm{~J}_{9}$ & $\mathrm{~J}_{1}$ & 107 & 9.66 & 11.9 \\
\hline & 36 & 37 & 55 & 65 & 74 & 84 & 89 & 95 & 103 & 107 & & & \\
\hline
\end{tabular}

Table 11: Results of DABC-II.

\begin{tabular}{|c|c|c|c|c|c|c|c|c|c|c|c|c|c|}
\hline \multirow{3}{*}{$\begin{array}{c}\text { Population } \\
\text { individual }\end{array}$} & \multicolumn{10}{|c|}{ Final job sequence $\&$ completion time } & TCT & \multirow{3}{*}{$\begin{array}{l}\text { MWT } \\
5.7\end{array}$} & \multirow{3}{*}{$\begin{array}{c}\text { MWE } \\
13.6\end{array}$} \\
\hline & $\mathrm{J}_{6}$ & $\mathrm{~J}_{3}$ & $\mathrm{~J}_{4}$ & $\mathrm{~J}_{7}$ & $\mathrm{~J}_{5}$ & $\mathrm{~J}_{8}$ & $\mathbf{J}_{9}$ & $\mathrm{~J}_{1}$ & $\mathrm{~J}_{0}$ & $\mathrm{~J}_{2}$ & \multirow{2}{*}{93} & & \\
\hline & 32 & 45 & 56 & 61 & 71 & 76 & 85 & 89 & 92 & 93 & & & \\
\hline \multirow[t]{2}{*}{2} & $\mathrm{~J}_{1}$ & $\mathbf{J}_{9}$ & $\mathrm{~J}_{3}$ & $\mathrm{~J}_{4}$ & $\mathrm{~J}_{5}$ & $\mathrm{~J}_{6}$ & $\mathrm{~J}_{7}$ & $\mathrm{~J}_{8}$ & $\mathrm{~J}_{2}$ & $\mathrm{~J}_{0}$ & \multirow[t]{2}{*}{94} & \multirow[t]{2}{*}{5.4} & \multirow[t]{2}{*}{14.47} \\
\hline & 27 & 42 & 52 & 62 & 72 & 77 & 83 & 87 & 88 & 94 & & & \\
\hline \multirow[t]{2}{*}{3} & $\mathrm{~J}_{6}$ & $\mathbf{J}_{7}$ & $\mathrm{~J}_{3}$ & $\mathbf{J}_{9}$ & $\mathrm{~J}_{0}$ & $\mathrm{~J}_{1}$ & $\mathbf{J}_{2}$ & $\mathrm{~J}_{5}$ & $\mathrm{~J}_{4}$ & $\mathrm{~J}_{8}$ & \multirow[t]{2}{*}{95} & \multirow[t]{2}{*}{5.54} & \multirow[t]{2}{*}{19.31} \\
\hline & 32 & 39 & 49 & 56 & 60 & 66 & 67 & 81 & 91 & 95 & & & \\
\hline \multirow[t]{2}{*}{4} & $\mathrm{~J}_{6}$ & $\mathrm{~J}_{7}$ & $\mathrm{~J}_{3}$ & $\mathbf{J}_{9}$ & $\mathrm{~J}_{0}$ & $\mathrm{~J}_{1}$ & $\mathbf{J}_{2}$ & $\mathrm{~J}_{5}$ & $\mathrm{~J}_{4}$ & $\mathrm{~J}_{8}$ & \multirow[t]{2}{*}{95} & \multirow[t]{2}{*}{5.54} & \multirow[t]{2}{*}{19.31} \\
\hline & 32 & 39 & 49 & 56 & 60 & 66 & 67 & 81 & 91 & 95 & & & \\
\hline \multirow[t]{2}{*}{5} & $\mathbf{J}_{7}$ & $\mathrm{~J}_{6}$ & $\mathrm{~J}_{3}$ & $\mathrm{~J}_{8}$ & $\mathrm{~J}_{9}$ & $\mathrm{~J}_{0}$ & $\mathrm{~J}_{1}$ & $\mathrm{~J}_{2}$ & $\mathrm{~J}_{5}$ & $\mathrm{~J}_{4}$ & \multirow[t]{2}{*}{96} & \multirow[t]{2}{*}{5.64} & \multirow[t]{2}{*}{19.0} \\
\hline & 35 & 43 & 53 & 57 & 64 & 66 & 70 & 71 & 86 & 96 & & & \\
\hline \multirow[t]{2}{*}{6} & $\mathrm{~J} 4$ & $\mathrm{~J}_{6}$ & $\mathrm{~J}_{0}$ & $\mathrm{~J}_{1}$ & $\mathrm{~J}_{2}$ & $\mathrm{~J}_{3}$ & $\mathrm{~J}_{5}$ & $\mathbf{J}_{7}$ & $\mathrm{~J}_{8}$ & $\mathrm{~J}_{9}$ & \multirow[t]{2}{*}{99} & \multirow[t]{2}{*}{6.2} & \multirow[t]{2}{*}{19.17} \\
\hline & 36 & 40 & 47 & 53 & 54 & 64 & 80 & 87 & 91 & 99 & & & \\
\hline \multirow[t]{2}{*}{7} & $\mathrm{~J}_{3}$ & $\mathrm{~J}_{4}$ & $\mathrm{~J}_{7}$ & $\mathrm{~J}_{5}$ & $\mathrm{~J}_{6}$ & $\mathrm{~J}_{8}$ & $\mathbf{J}_{9}$ & $\mathrm{~J}_{0}$ & $\mathrm{~J}_{1}$ & $\mathrm{~J}_{2}$ & \multirow[t]{2}{*}{97} & \multirow[t]{2}{*}{7.52} & \multirow[t]{2}{*}{11.19} \\
\hline & 43 & 54 & 59 & 69 & 74 & 78 & 87 & 90 & 96 & 97 & & & \\
\hline \multirow[t]{2}{*}{8} & $\mathrm{~J}_{5}$ & $\mathrm{~J}_{3}$ & $\mathrm{~J}_{1}$ & $\mathrm{~J}_{6}$ & $\mathrm{~J}_{7}$ & $\mathrm{~J}_{8}$ & $\mathbf{J}_{9}$ & $\mathrm{~J}_{0}$ & $\mathrm{~J}_{2}$ & $\mathrm{~J}_{4}$ & \multirow[t]{2}{*}{101} & \multirow[t]{2}{*}{8.41} & 8.43 \\
\hline & 55 & 65 & 69 & 73 & 78 & 82 & 89 & 91 & 92 & 101 & & & \\
\hline 9 & $\mathrm{~J}_{5}$ & $\mathrm{~J}_{7}$ & $\mathrm{~J}_{8}$ & $\mathrm{~J}_{9}$ & $\mathrm{~J}_{0}$ & $\mathrm{~J}_{1}$ & $\mathrm{~J}_{6}$ & $\mathrm{~J}_{2}$ & $\mathrm{~J}_{3}$ & $\mathrm{~J}_{4}$ & 106 & 9.96 & 9.19 \\
\hline & 55 & 62 & 66 & 74 & 77 & 83 & 87 & 88 & 98 & 106 & & & \\
\hline 10 & $\mathrm{~J}_{7}$ & $\mathrm{~J}_{8}$ & $\mathrm{~J}_{5}$ & $\mathbf{J}_{9}$ & $\mathrm{~J}_{0}$ & $\mathrm{~J}_{1}$ & $\mathbf{J}_{2}$ & $\mathrm{~J}_{3}$ & $\mathrm{~J}_{4}$ & $\mathrm{~J}_{6}$ & 106 & 9.3 & 9.9 \\
\hline & 35 & 39 & 64 & 74 & 77 & 83 & 84 & 94 & 102 & 106 & & & \\
\hline
\end{tabular}

Table 12: Results of DABC-III.

\subsubsection{Discussion and time complexity analysis of DABC algorithm}

The DABC algorithm is tested under three types of scenarios using the local search algorithms such as twoswap (), three-swap (), two- insert (), three-insert () and destruct-construct () iteratively. Each time a random local search algorithm is used to find out nearest optimal solutions. To achieve the population diversity we have used the selection strategy of selecting proportionately equal number of solutions from each objective function. In the small-sized input data we see that many times the resulted sequences are being repeated because of less number of jobs, which is a rare in the large one. We checked the complexity of these algorithms in terms of number of machines (M) and number of jobs (N). 


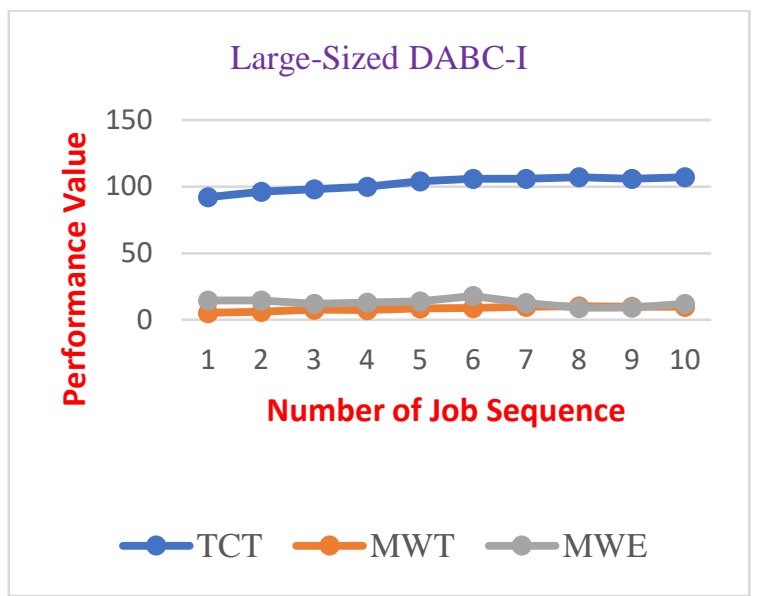

Figure 13: Graphical representation of DABC-I.

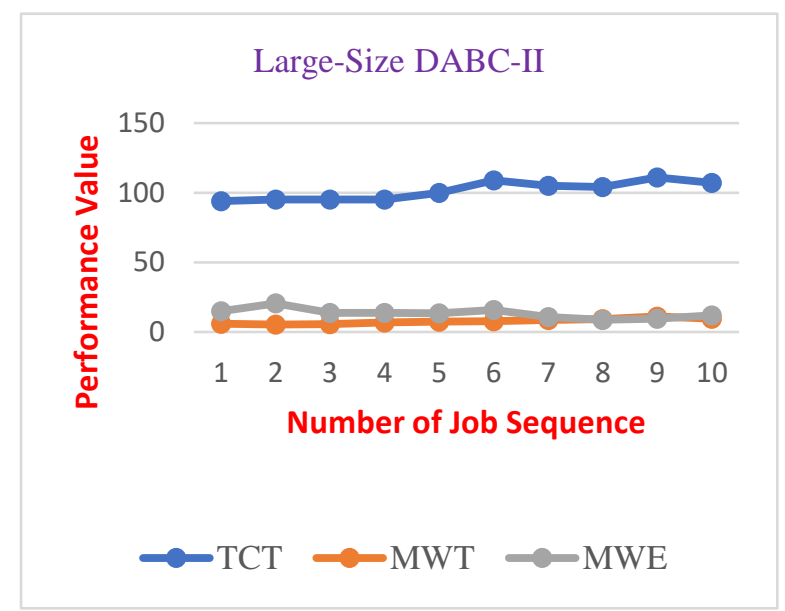

Figure 14: Graphical representation of DABC-II.

\begin{tabular}{|c|c|}
\hline $\begin{array}{l}\text { Local-search } \\
\text { algorithms }\end{array}$ & Time complexity \\
\hline Two-swap & $\mathrm{O}(\mathrm{MN})$ \\
\hline Three-swap() & $\mathrm{O}(\mathrm{MN})$ \\
\hline Two-insert() & $\mathrm{O}(\mathrm{MN})$ \\
\hline Three-insert() & $\mathrm{O}(\mathrm{MN})$ \\
\hline Construct-destruct() & $\mathrm{O}\left(\mathrm{MN}^{2}\right)$ \\
\hline
\end{tabular}

Table 13: Time complexity analysis of local search algorithms.

We have used these functions alternatively in DABC-I, DABC-II and DABC-III, and see that using construct-destruct (), the algorithm is not giving any significant improvement in the result. Based on the time complexity of different local search methods, we conclude that DABC-I is better than DABC-II and DABC-II is better than DABC-III.

\subsubsection{Results and discussions through MOABC}

While optimizing three objectives through MOABC, a number of non-dominated solutions are resulted and are listed below with their respective Pareto fronts. Here we do not find any abandoned solutions as there was no solution in the final archive having trial counter value more than 20 . In the small-size dataset there are '7' non-

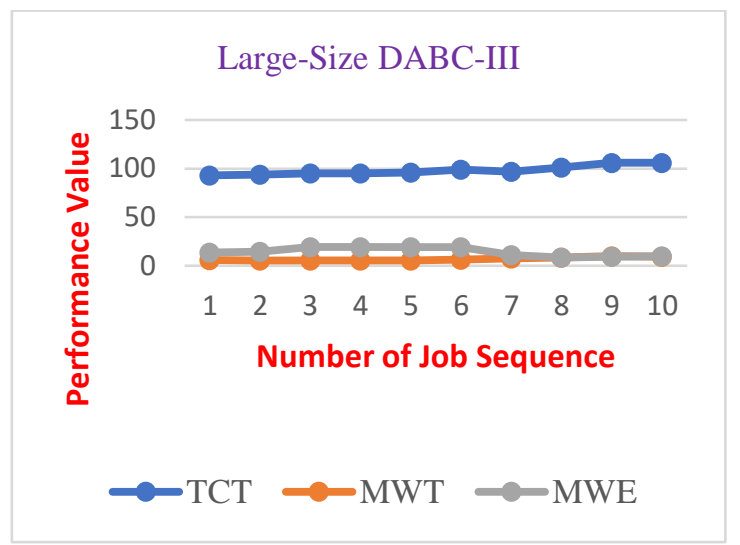

Figure 15: Graphical representation of DABC-III.

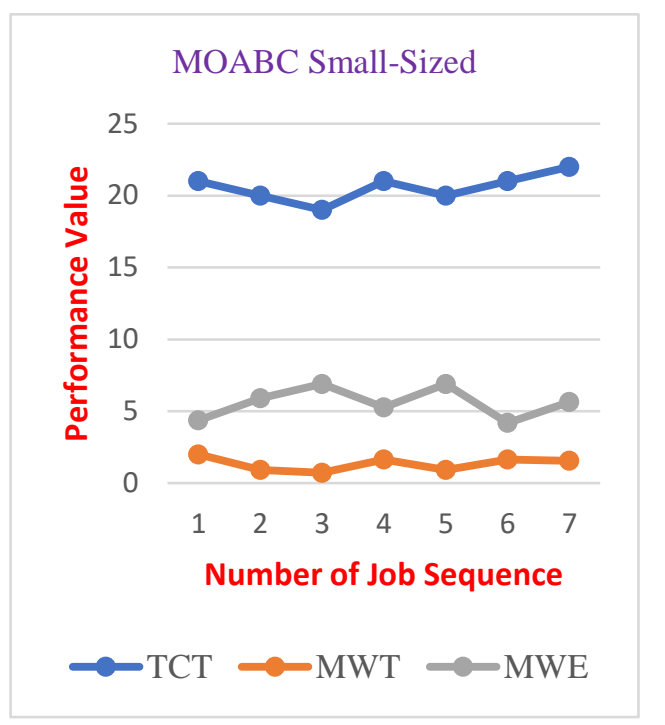

Figure 16: Pareto front (small-size).

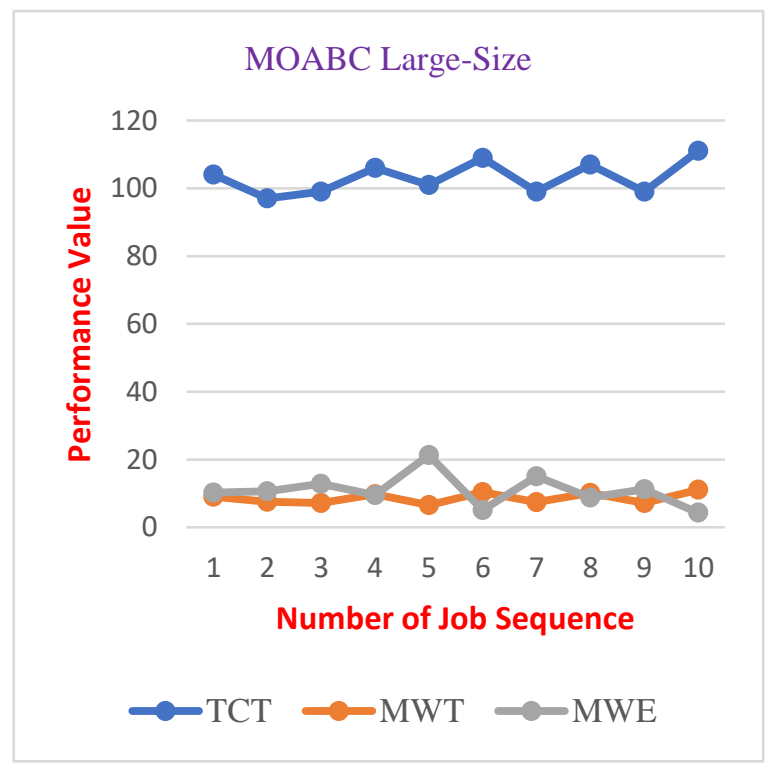

Figure 17: Pareto front (large-size).

dominated sets and the large one is resulting 10 such solutions in the resulting Pareto front. 


\begin{tabular}{|c|c|c|c|c|c|c|c|}
\hline \multirow[t]{3}{*}{$\mathrm{P}$} & \multicolumn{4}{|c|}{$\begin{array}{l}\text { Final job sequence } \\
\& \text { completion time }\end{array}$} & \multirow{3}{*}{$\begin{array}{l}\text { TCT } \\
21\end{array}$} & \multirow{3}{*}{$\begin{array}{l}\text { MW } \\
\text { T } \\
2.0\end{array}$} & \multirow{2}{*}{$\begin{array}{l}\text { MW } \\
\text { E } \\
4.36\end{array}$} \\
\hline & $\mathrm{J}_{0}$ & $\mathrm{~J}_{1}$ & $\mathrm{~J}_{3}$ & $\mathrm{~J}_{2}$ & & & \\
\hline & 12 & 14 & 18 & 21 & & & \\
\hline \multirow[t]{2}{*}{2} & $\mathrm{~J}_{3}$ & $\mathrm{~J}_{1}$ & $\mathrm{~J}_{2}$ & $\mathrm{~J}_{0}$ & \multirow[t]{2}{*}{20} & \multirow[t]{2}{*}{0.9} & \multirow[t]{2}{*}{5.9} \\
\hline & 9 & 11 & 15 & 20 & & & \\
\hline \multirow[t]{2}{*}{3} & $\mathrm{~J}_{1}$ & $\mathrm{~J}_{3}$ & $\mathrm{~J}_{0}$ & $\mathrm{~J}_{2}$ & \multirow[t]{2}{*}{19} & \multirow[t]{2}{*}{0.72} & \multirow[t]{2}{*}{6.9} \\
\hline & 5 & 10 & 15 & 19 & & & \\
\hline \multirow[t]{2}{*}{4} & $\mathrm{~J}_{3}$ & $\mathrm{~J}_{2}$ & $\mathrm{~J}_{1}$ & $\mathbf{J}_{0}$ & \multirow[t]{2}{*}{21} & \multirow[t]{2}{*}{1.63} & \multirow[t]{2}{*}{5.27} \\
\hline & 9 & 14 & 16 & 21 & & & \\
\hline \multirow[t]{2}{*}{5} & $\mathrm{~J}_{1}$ & $\mathrm{~J}_{3}$ & $\mathrm{~J}_{2}$ & $\mathrm{~J}_{0}$ & \multirow[t]{2}{*}{20} & \multirow[t]{2}{*}{0.90} & \multirow[t]{2}{*}{6.9} \\
\hline & & 10 & 15 & 20 & & & \\
\hline \multirow[t]{2}{*}{6} & $\mathrm{~J}_{3}$ & $\mathrm{~J}_{2}$ & $\mathrm{~J}_{0}$ & $\mathrm{~J}_{1}$ & \multirow[t]{2}{*}{21} & \multirow[t]{2}{*}{1.63} & \multirow[t]{2}{*}{4.18} \\
\hline & 9 & 14 & 19 & 21 & & & \\
\hline \multirow[t]{2}{*}{7} & $\mathrm{~J}_{1}$ & $\mathrm{~J}_{2}$ & $\mathrm{~J}_{3}$ & $\mathrm{~J}_{0}$ & \multirow[t]{2}{*}{22} & \multirow[t]{2}{*}{1.54} & \multirow[t]{2}{*}{5.63} \\
\hline & 5 & 13 & 17 & 22 & & & \\
\hline
\end{tabular}

Table 14: Non-dominated job sequence.

\subsubsection{Small-size dataset}

7 non-dominated solutions emerged from the first dataset and are listed in Table 14. These solutions can be further evaluated by the decision maker to reach at the definite goal.

The resulted non-dominated set of table 14 has been depicted to the corresponding Pareto front in figure 16 . The 3 objectives fitness values show a clear graphical visualization of the non-dominated set.

\subsubsection{Large-size dataset}

Table 15 stores the 10 non-dominated solutions emerged from the large-sized dataset. Each solution is represented with individual job completion time and finally the TCT value of the same sequence, followed by MWT and MWE respectively.

Each best fitted solution for the large-sized dataset is captured as its Pareto front and is represented in figure 18 , with its respective fitness values.

The MOABC also yields equally compromising optimized solutions as that of DABC algorithm. The results reveal that the proposed algorithms are superior enough to deal with multi-objectives with a little parameter variation to the canonical $\mathrm{ABC}$. It is a straight forward extension of uni-objective $\mathrm{ABC}$ with mixing advantages of local search procedure from the proposed DABC algorithm. We have just applied one of the simplest local search procedure that is two-swap () procedure to optimize the local optima which definitely helps in reducing the algorithmic complexity.

From the result analysis, apart from the completion time, it is seen that most of time the earliness penalty is more than the tardiness penalty. Hence with a required priority level of all the objectives a decision maker can easily go for making a balanced decision for him by applying a suitable MCDM method.

\section{Decision making with chaotic- TOPSIS}

After generating successful optimized solution set, we cannot avoid for selecting an appropriate one among these during the decision making process. MCDM is a successful tool for decision making with conflicting

\begin{tabular}{|c|c|c|c|c|c|c|c|c|c|c|c|c|c|}
\hline $\mathrm{P}$ & \multicolumn{10}{|c|}{ Final job sequence \& completion time } & TCT & MWT & MWE \\
\hline \multirow[t]{2}{*}{1} & $\mathrm{~J}_{2}$ & $\mathrm{~J}_{3}$ & $\mathrm{~J}_{4}$ & $\mathrm{~J}_{5}$ & $\mathrm{~J}_{6}$ & $\mathrm{~J}_{7}$ & $\mathrm{~J}_{8}$ & $\mathbf{J}_{9}$ & $\mathrm{~J}_{0}$ & $\mathrm{~J}_{1}$ & \multirow[t]{2}{*}{104} & \multirow[t]{2}{*}{8.96} & \multirow[t]{2}{*}{10.27} \\
\hline & 24 & 51 & 62 & 72 & 77 & 83 & 87 & 95 & 98 & 104 & & & \\
\hline \multirow[t]{2}{*}{2} & $\mathrm{~J}_{3}$ & $\mathrm{~J}_{4}$ & $\mathrm{~J}_{5}$ & $\mathrm{~J}_{6}$ & $\mathrm{~J}_{7}$ & $\mathrm{~J}_{8}$ & $\mathrm{~J}_{9}$ & $\mathrm{~J}_{0}$ & $\mathrm{~J}_{1}$ & $\mathrm{~J}_{2}$ & \multirow[t]{2}{*}{97} & \multirow[t]{2}{*}{7.54} & \multirow[t]{2}{*}{10.60} \\
\hline & 43 & 54 & 64 & 69 & 75 & 79 & 87 & 90 & 96 & 97 & & & \\
\hline \multirow[t]{2}{*}{3} & $\mathrm{~J}_{4}$ & $\mathrm{~J}_{5}$ & $\mathrm{~J}_{6}$ & $\mathrm{~J}_{7}$ & $\mathrm{~J}_{8}$ & $\mathrm{~J}_{9}$ & $\mathrm{~J}_{0}$ & $\mathrm{~J}_{1}$ & $\mathrm{~J}_{2}$ & $\mathrm{~J}_{3}$ & \multirow[t]{2}{*}{99} & \multirow[t]{2}{*}{7.19} & \multirow[t]{2}{*}{12.86} \\
\hline & 36 & 56 & 61 & 67 & 71 & 79 & 82 & 88 & 89 & 99 & & & \\
\hline \multirow[t]{2}{*}{4} & $\mathrm{~J}_{5}$ & $\mathrm{~J}_{6}$ & $\mathrm{~J}_{7}$ & $\mathrm{~J}_{8}$ & $\mathrm{~J}_{9}$ & $\mathrm{~J}_{0}$ & $\mathrm{~J}_{1}$ & $\mathrm{~J}_{2}$ & $\mathrm{~J}_{3}$ & $\mathrm{~J}_{4}$ & \multirow[t]{2}{*}{106} & \multirow[t]{2}{*}{9.8} & \multirow[t]{2}{*}{9.47} \\
\hline & 55 & 60 & 66 & 70 & 78 & 81 & 87 & 88 & 98 & 106 & & & \\
\hline \multirow[t]{2}{*}{5} & $\mathrm{~J}_{6}$ & $\mathrm{~J}_{7}$ & $\mathrm{~J}_{8}$ & $\mathrm{~J}_{9}$ & $\mathbf{J}_{0}$ & $\mathrm{~J}_{1}$ & $\mathrm{~J}_{2}$ & $\mathrm{~J}_{3}$ & $\mathrm{~J}_{4}$ & $\mathrm{~J}_{5}$ & \multirow[t]{2}{*}{101} & \multirow[t]{2}{*}{6.54} & \multirow[t]{2}{*}{21.29} \\
\hline & 32 & 39 & 43 & 51 & 57 & 63 & 64 & 80 & 91 & 101 & & & \\
\hline \multirow[t]{2}{*}{6} & $\mathrm{~J}_{0}$ & $\mathrm{~J}_{1}$ & $\mathrm{~J}_{5}$ & $\mathrm{~J}_{3}$ & $\mathrm{~J}_{4}$ & $\mathrm{~J}_{2}$ & $\mathrm{~J}_{6}$ & $\mathrm{~J}_{7}$ & $\mathbf{J}_{8}$ & $\mathbf{J}_{9}$ & \multirow[t]{2}{*}{109} & \multirow[t]{2}{*}{10.39} & \multirow[t]{2}{*}{5.03} \\
\hline & 43 & 49 & 70 & 80 & 88 & 89 & 93 & 98 & 102 & 109 & & & \\
\hline \multirow[t]{2}{*}{7} & $\mathrm{~J}_{1}$ & $\mathrm{~J}_{2}$ & $\mathrm{~J}_{6}$ & $\mathrm{~J}_{4}$ & $\mathrm{~J}_{5}$ & $\mathrm{~J}_{3}$ & $\mathrm{~J}_{7}$ & $\mathrm{~J}_{8}$ & $\mathbf{J}_{9}$ & $\mathrm{~J}_{0}$ & \multirow[t]{2}{*}{99} & \multirow[t]{2}{*}{7.37} & \multirow[t]{2}{*}{15.01} \\
\hline & 27 & 29 & 50 & 60 & 71 & 81 & 86 & 90 & 97 & 99 & & & \\
\hline \multirow[t]{2}{*}{8} & $\mathrm{~J}_{2}$ & $\mathrm{~J}_{3}$ & $\mathrm{~J}_{7}$ & $\mathrm{~J}_{5}$ & $\mathrm{~J}_{6}$ & $\mathrm{~J}_{4}$ & $\mathrm{~J}_{8}$ & $\mathrm{~J}_{9}$ & $\mathrm{~J}_{0}$ & $\mathrm{~J}_{1}$ & \multirow[t]{2}{*}{107} & \multirow[t]{2}{*}{10.15} & 8.76 \\
\hline & 24 & 51 & 61 & 74 & 79 & 89 & 93 & 100 & 102 & 107 & & & \\
\hline 9 & $\mathrm{~J}_{4}$ & $\mathrm{~J}_{5}$ & $\mathrm{~J}_{9}$ & $\mathrm{~J}_{7}$ & $\mathrm{~J}_{8}$ & $\mathrm{~J}_{6}$ & $\mathrm{~J}_{0}$ & $\mathrm{~J}_{1}$ & $\mathrm{~J}_{2}$ & $\mathrm{~J}_{3}$ & 99 & 7.19 & 11.21 \\
\hline & 36 & 56 & 66 & 71 & 75 & 79 & 82 & 88 & 89 & 99 & & & \\
\hline 10 & $\mathrm{~J}_{0}$ & $\mathrm{~J}_{1}$ & $\mathrm{~J}_{5}$ & $\mathrm{~J}_{4}$ & $\mathrm{~J}_{3}$ & $\mathrm{~J}_{2}$ & $\mathrm{~J}_{6}$ & $\mathrm{~J}_{7}$ & $\mathrm{~J}_{8}$ & $\mathrm{~J}_{9}$ & 111 & 11.05 & 4.29 \\
\hline & 43 & 49 & 70 & 80 & 90 & 91 & 95 & 100 & 104 & 111 & & & \\
\hline
\end{tabular}

Table 15: Non-dominated job sequence. 
criterion. Various methods show their respective efficiency in this regard. By a comparative survey we have concluded to decide the final optimal solution here with in our problem using TOPSIS method which really seems to be fit.We have summarized some of the recent TOPSIS applications followed by the discussions of our motivation.

Li et al. [47] presents a new method based on TOPSIS and response surface method (RSM) for MCDM problems with interval number. Similarly Madi et al. [48] provided a detailed comparison of TOPSIS and FuzzyTOPSIS in a systematic and stepwise manner. SotoudehAnvari [49] suggested a stochastic multi-objective optimization model for assigning resource and time in order to search the individuals who are trapped in disaster regions. To reduce the heavy computation of the model, two efficient MCDM techniques, i.e. TOPSIS and COPRAS are employed which tackles the ranking problem. Zavadskas et al. [50] reviewed 105 papers which developed, extended, proposed and presented TOPSIS approach for solving DM problems from 2000 to 2015. Recently $\mathrm{Wu}$ et al.[51] proposes an improved methodology for handling ships which uses TOPSIS method to make the final decision.

\section{TOPSIS}

TOPSIS was developed by Hwang and Yoon [52] in the year of 1981 as an alternative to the elimination and choice translating reality (ELECTRE) method. The basic idea of TOPSIS is quite simple and it has been originated from a displaced ideal point from which the selected solution has shortest distance [53-54]. Further it is refined [52] to the rank based method by assigning specific orders to the available alternatives. The whole concept is based on the two artificial ideal points; that is the ultimate solution is measured by having longest distance from the positive ideal solution (PIS) and the shortest from the negative ideal solution (NIS). Hence a preference order of all alternatives is generated as per their relative closeness to the ideal solutions. As concluded by Kim et al. [55] and our observations, basic TOPSIS advantages are recorded as:

It is an accepted logic that is focused to rationale of human choice;

A scalar value justifies both the ideal alternatives together;

coded to the spreadsheet;

(iv) A straightforward performance evaluation of all alternatives against the defined criteria which can be clearly visualized and represented for two or more dimensions.

The above defined advantages make TOPSIS an omnipresent MCDM technique as compared with rest techniques [52]. In fact it is a utility-based method that evaluates every alternative directly depending on the available data in the decision matrices and weights [56]. Apart from this, the simulation comparison [57] of TOPSIS method signifies that it has the fewest rank reversals apart from rest methods in the category. Thus, TOPSIS is chosen as the backbone of MCDM.

The preliminary issue with the method is the normalized decision matrix operation, where randomness is achieved while assigning the criterion weights. Hence a narrow gap derived between the performed measures due to the weighted normalized value of the decision matrix. It can be advantageous to substitute this randomness with a suitable chaotic map. Chaos has a very similar property to randomness with better statistical and dynamical characteristic. Such a dynamic mixing is truly appreciated to enhance solutions potentiality by touching every mode in a multi-objective landscape. Hence the use of a well-suit chaotic map in TOPSIS can be definitely helpful to enhance the decision making by generating preferred randomness in criterion weight.

\section{Chaotic maps}

Simulation of complex phenomena such as: numerical analysis, decision making, sampling, heuristic optimization etc. needs random sequences for a longer period and good uniformity [58]. Chaotic map is a deterministic, discrete-time dynamic system that is considered as source of randomness, which is nonperiod, bounded and non-converging [59-60]. However the nature of chaotic maps is apparently random, unpredictable and it has a very sensitive dependence on its initial condition and parameter [58].

A chaotic map can be represented as:

$x_{k+1}=f\left(x_{k}\right), 0, x_{k}<1, k=0,1,2,3 .$.

Different selected chaotic maps that produce chaotic numbers in $[0,1]$ are listed below in table 16 [59-60].

\begin{tabular}{|c|c|}
\hline Chao Map & Definition \\
\hline $\begin{array}{l}\text { Logistic } \\
\text { Map }\end{array}$ & $x_{n+1}=4 x_{n}\left(1-x_{n}\right)$ \\
\hline Circle Map & $x_{n+1}=x_{n}+1.2-\left(0.5 / 2 \pi x_{n}\right) \bmod (1)$ \\
\hline Gauss Map & $\begin{array}{l}x_{n}=\left\{\begin{array}{ll}0, & x_{n}=0 \\
1 / x_{n} \bmod (1), & \text { otherwise }\end{array}\right\} \\
1 / x_{k} \bmod (1)=1 / x_{k}-\left[1 / x_{k}\right]\end{array}$ \\
\hline $\begin{array}{l}\text { Henon } \\
\text { Map }\end{array}$ & $x_{n+1}=1-1.4 x_{n}^{2}+0.3 x_{n-1}$ \\
\hline $\begin{array}{l}\text { Sinusoidal } \\
\text { Map }\end{array}$ & $x_{n+1}=\sin \left(\pi x_{n}\right)$ \\
\hline Sinus Map & $x_{n+1}=2.3\left(x_{n}\right)^{2 \sin \left(\pi x_{n}\right)}$ \\
\hline Tent Map & $x_{n+1}=\left\{\begin{array}{ll}x_{n} / 0.7, & x_{n}<0.7 \\
10 / 3 x_{n}\left(1-x_{n}\right), & \text { otherwise }\end{array}\right\}$ \\
\hline
\end{tabular}

Table 16: Different Chaotic Maps. 


\begin{tabular}{|r|l|l|l|l|l|}
\hline $\begin{array}{l}\text { Altern- } \\
\text { ative }\end{array}$ & TCT & MWT & MWE & $\begin{array}{l}\text { Closeness } \\
\text { coefficient }\end{array}$ & Rank \\
\hline $\mathrm{A}_{1}$ & 19 & 0.72 & 5.54 & 0.1524 & 10 \\
\hline $\mathrm{A}_{2}$ & 20 & 0.9 & 5.9 & 0.2130 & 9 \\
\hline $\mathrm{A}_{3}$ & 21 & 2.0 & 4.36 & 0.5606 & 5 \\
\hline $\mathrm{A}_{4}$ & 21 & 1.3 & 5.6 & 0.3238 & 8 \\
\hline $\mathrm{A}_{5}$ & 22 & 1.54 & 5.27 & 0.4201 & 7 \\
\hline $\mathrm{A}_{6}$ & 22 & 1.54 & 5.63 & 0.4302 & 6 \\
\hline $\mathrm{A}_{7}$ & 23 & 2.36 & 4.0 & 0.7036 & 4 \\
\hline $\mathrm{A}_{8}$ & 21 & 2.54 & 4.0 & 0.7278 & 3 \\
\hline $\mathrm{A}_{9}$ & 21 & 2.54 & 4.36 & 0.7475 & 2 \\
\hline $\mathrm{A}_{10}$ & 23 & 2.9 & 4.36 & 0.8476 & 1 \\
\hline
\end{tabular}

Table 17: Alternatives from DABC-I.

\begin{tabular}{|l|l|l|l|l|l|}
\hline $\begin{array}{l}\text { Altern- } \\
\text { ative }\end{array}$ & TCT & MWT & MWE & $\begin{array}{l}\text { Closeness } \\
\text { coefficient }\end{array}$ & Rank \\
\hline $\mathrm{A}_{1}$ & 19 & 0.72 & 6.9 & 0.2462 & 7 \\
\hline $\mathrm{A}_{2}$ & 19 & 1.27 & 5.27 & 0.2515 & 6 \\
\hline $\mathrm{A}_{3}$ & 20 & 0.90 & 6.9 & 0.2704 & 5 \\
\hline $\mathrm{A}_{4}\left(\mathrm{~A}_{5}, \mathrm{~A}_{6}\right)$ & 21 & 1.63 & 5.27 & 0.3907 & 3 \\
\hline $\mathrm{A}_{7}$ & 21 & 1.63 & 4.18 & 0.3604 & 4 \\
\hline $\mathrm{A}_{8}\left(\mathrm{~A}_{9}\right)$ & 22 & 2.72 & 3.63 & 0.6813 & 2 \\
\hline $\mathrm{A}_{10}$ & 23 & 3.18 & 4.0 & 0.7755 & 1 \\
\hline
\end{tabular}

Table 18: Alternatives from DABC-II.

\begin{tabular}{|l|l|l|l|c|r|}
\hline $\begin{array}{l}\text { Altern- } \\
\text { ative }\end{array}$ & TCT & MWT & MWE & $\begin{array}{l}\text { Closeness } \\
\text { coefficient }\end{array}$ & Rank \\
\hline $\mathrm{A}_{1}$ & 20 & 1.45 & 4.54 & $\begin{array}{l}0.179 \\
6\end{array}$ & 8 \\
\hline $\mathrm{A}_{2}$ & 21 & 2.0 & 4.36 & $\begin{array}{l}0.396 \\
7\end{array}$ & 6 \\
\hline $\mathrm{A}_{3}$ & 21 & 2.54 & 4.0 & $\begin{array}{l}0.668 \\
8\end{array}$ & 5 \\
\hline $\mathrm{A}_{4}$ & 21 & 2.54 & 4.36 & $\begin{array}{l}0.687 \\
3\end{array}$ & 4 \\
\hline $\mathrm{A}_{5}\left(\mathrm{~A}_{6}\right)$ & 21 & 1.63 & 4.18 & $\begin{array}{l}0.198 \\
3\end{array}$ & 7 \\
\hline $\mathrm{A}_{7}$ & 22 & 2.72 & 3.63 & $\begin{array}{l}0.756 \\
4\end{array}$ & 3 \\
\hline $\mathrm{A}_{8}\left(\mathrm{~A}_{9)}\right.$ & 23 & 2.9 & 4.3 & $\begin{array}{l}0.946 \\
1\end{array}$ & 1 \\
\hline $\mathrm{A}_{10}$ & 22 & 2.72 & 4.36 & $\begin{array}{l}0.835 \\
6\end{array}$ & 2 \\
\hline
\end{tabular}

Table 19: Alternatives from DABC-III.

Again it is a challenging task to find out a proper and suitable chaotic function to well fit to our decision making problem. Researchers used a number of chaotic sequences to tune various parameters in various metaheuristic optimization algorithms such as particle swarm optimization[61-62], genetic algorithms[63], harmony search[60], imperialist competitive algorithm [64], ant and bee colony optimization [65, 59], firefly algorithm [62] and simulated annealing [66]. Each research in different direction has shown some promise once the right set of chaotic maps is applied. Gandomi and Yang [67] founds sinusoidal map is the most suitable for the bat algorithm to replace with loudness and pulse rate

\begin{tabular}{|l|l|l|l|l|l|}
\hline $\begin{array}{l}\text { Altern } \\
\text {-ative }\end{array}$ & TCT & MWT & MWE & $\begin{array}{l}\text { Closeness } \\
\text { coeff }\end{array}$ & Rank \\
\hline $\mathrm{A}_{1}$ & 92 & 5.21 & 14.43 & 0.2960 & 10 \\
\hline $\mathrm{A}_{2}$ & 96 & 6.11 & 14.6 & 0.3667 & 9 \\
\hline $\mathrm{A}_{3}$ & 98 & 7.49 & 11.94 & 0.4132 & 8 \\
\hline $\mathrm{A}_{4}$ & 100 & 7.25 & 12.84 & 0.4320 & 7 \\
\hline $\mathrm{A}_{5}$ & 104 & 8.68 & 14.0 & 0.6617 & 3 \\
\hline $\mathrm{A}_{6}$ & 106 & 8.84 & 17.8 & 0.8070 & 1 \\
\hline $\mathrm{A}_{7}$ & 106 & 9.7 & 12.52 & 0.6873 & 2 \\
\hline $\mathrm{A}_{8}$ & 107 & 10.17 & 9.0 & 0.5862 & 5 \\
\hline $\mathrm{A}_{9}$ & 106 & 9.7 & 9.11 & 0.5640 & 6 \\
\hline $\mathrm{A}_{10}$ & 107 & 9.66 & 11.9 & 0.6613 & 4 \\
\hline
\end{tabular}

Table 20: Alternatives from DABC-I.

\begin{tabular}{|l|l|l|l|l|l|}
\hline $\begin{array}{l}\text { Altern } \\
\text {-ative }\end{array}$ & TCT & MWT & MWE & $\begin{array}{l}\text { Closeness } \\
\text { coefficient }\end{array}$ & Rank \\
\hline $\mathrm{A}_{1}$ & 94 & 6.07 & 14.82 & 0.2946 & 9 \\
\hline $\mathrm{A}_{2}$ & 95 & 5.3 & 20.49 & 0.4250 & 6 \\
\hline $\mathrm{A}_{3}$ & 95 & 5.74 & 13.64 & 0.2352 & 10 \\
\hline $\mathrm{A}_{4}$ & 95 & 6.8 & 13.6 & 0.3047 & 8 \\
\hline $\mathrm{A}_{5}$ & 100 & 7.5 & 13.47 & 0.3839 & 7 \\
\hline $\mathrm{A}_{6}$ & 109 & 7.78 & 15.82 & 0.5232 & 3 \\
\hline $\mathrm{A}_{7}$ & 105 & 8.7 & 10.6 & 0.4484 & 4 \\
\hline $\mathrm{A}_{8}$ & 104 & 9.17 & 8.76 & 0.4466 & 5 \\
\hline $\mathrm{A}_{9}$ & 111 & 11.13 & 9.45 & 0.5918 & 1 \\
\hline $\mathrm{A}_{10}$ & 107 & 9.66 & 11.9 & 0.5668 & 2 \\
\hline
\end{tabular}

Table 21: Alternatives from DABC-II.

respectively. Similarly Gandomi et al. [61] have experimented twelve different chaotic maps to tune the major parameters of PSO. They revealed sinusoidal map and singer map perform better result in comparison to the rest. Talatahari et al.[64] proposed in a novel chaotic improved imperialist competitive algorithm by investing seven different chaotic maps and sinusoidal and logistic maps are found as the best choices. Also in Gandomi et al. [62] experimentally revealed sinusoidal map and gauss maps are the best performed chao to be adopted for firefly algorithm. Most experimental results proved sinusoidal as a common better performing random generator. By watching the efficiency of sinusoidal map, we have used the same to find out the random numbers in the TOPSIS weight assignment procedure. Again it is important for the decision maker to maintain the priority level of all criterions. To cope up with this we have sorted the random numbers and assigned them to the respective criterions.

\section{Decision results}

To finalize the decision results we have generated a set of three chaotic numbers using sinusoidal map and sorted them to represent different criterion weights. With respect to each decision matrix we have allotted the same criterion weight, in a preference order i.e., $\{0.5,0.3,0.2\}$. Here we have assumed of TCT with highest preference, 


\begin{tabular}{|l|l|l|l|l|l|}
\hline $\begin{array}{l}\text { Altern } \\
\text {-ative }\end{array}$ & TCT & MWT & $\begin{array}{l}\text { MW } \\
\text { E }\end{array}$ & $\begin{array}{l}\text { Closen } \\
\text { ess } \\
\text { coeffic } \\
\text { ient }\end{array}$ & Rank \\
\hline $\mathrm{A}_{1}$ & 94 & 6.07 & 14.82 & 0.2946 & 9 \\
\hline $\mathrm{A}_{2}$ & 95 & 5.3 & 20.49 & 0.4250 & 6 \\
\hline $\mathrm{A}_{3}$ & 95 & 5.74 & 13.64 & 0.2352 & 10 \\
\hline $\mathrm{A}_{4}$ & 95 & 6.8 & 13.6 & 0.3047 & 8 \\
\hline $\mathrm{A}_{5}$ & 100 & 7.5 & 13.47 & 0.3839 & 7 \\
\hline $\mathrm{A}_{6}$ & 109 & 7.78 & 15.82 & 0.5232 & 3 \\
\hline $\mathrm{A}_{7}$ & 105 & 8.7 & 10.6 & 0.4484 & 4 \\
\hline $\mathrm{A}_{8}$ & 104 & 9.17 & 8.76 & 0.4466 & 5 \\
\hline $\mathrm{A}_{9}$ & 111 & 11.13 & 9.45 & 0.5918 & 1 \\
\hline $\mathrm{A}_{10}$ & 107 & 9.66 & 11.9 & 0.5668 & 2 \\
\hline $\mathrm{A}_{1}$ & 93 & 5.7 & 13.6 & 0.2540 & 9 \\
\hline $\mathrm{A}_{2}$ & 94 & 5.4 & 14.47 & 0.2760 & 8 \\
\hline $\mathrm{A}_{3}\left(\mathrm{~A}_{4}\right)$ & 95 & 5.54 & 19.31 & 0.4281 & 6 \\
\hline $\mathrm{A}_{5}$ & 96 & 5.64 & 19.0 & 0.4291 & 5 \\
\hline $\mathrm{A}_{6}$ & 99 & 6.2 & 19.17 & 0.4806 & 3 \\
\hline $\mathrm{A}_{7}$ & 97 & 7.52 & 11.19 & 0.3873 & 7 \\
\hline $\mathrm{A}_{8}$ & 101 & 8.41 & 8.43 & 0.4526 & 4 \\
\hline $\mathrm{A}_{9}$ & 106 & 9.96 & 9.19 & 0.6012 & 1 \\
\hline $\mathrm{A}_{10}$ & 106 & 9.3 & 9.9 & 0.5810 & 2 \\
\hline
\end{tabular}

Table 22: Alternatives from DABC-III.

then MWT and lastly MWE. The decision matrices are nothing but various resulted non-dominated sequences of TCT, MWT and MWE. For every individual decision matrix we have generated the closeness coefficient value w.r.t both the ideal solutions and so as the ranks. Firstly we have calculated the ranks of all the alternatives generated from DABC-I, DABC-II and DABC-III for the small-size dataset followed by the large one. Lastly the alternatives from MOABC are evaluated in the same sequence.

\section{DABC (Small-sized)}

Table 17 represents the alternatives generated from DABC-I. 10 alternatives are evaluated with the proposed chao-TOPSIS procedure and the ranks are presented. Alternative $\mathrm{A}_{10}$ is having highest closeness coefficient value than all, hence is chosen as rank 1 alternative for the decision maker.

The non-dominated sequences of DABC-II (Table 18) are having some of the repeating sequences; hence they are treated as one single alternative. Alternatives $\mathrm{A}_{4}$, $\mathrm{A}_{5}, \mathrm{~A}_{6}$ are the same sequences and that of alternatives $\mathrm{A}_{8}$ and $A_{9}$. These repeating sequences are the result of selecting the proportionately best fitness values from each objective function and application of local search algorithms repeatedly to a small sized data set. Hence altogether we have evaluated 7 sequences and the last alternative $A_{10}$ is the best ranked.

Similarly table 19 contains the resulting sequences of DABC-III. Out of 10 sequences two pairs $\left(\left(\mathrm{A}_{5}=\mathrm{A}_{6}\right)\right.$ and

\begin{tabular}{|l|l|l|l|l|l|}
\hline $\begin{array}{l}\text { Altern } \\
\text {-ative }\end{array}$ & TCT & MWT & MWE & $\begin{array}{l}\text { Closenes } \\
\text { s coeff }\end{array}$ & Rank \\
\hline $\mathrm{A}_{1}$ & 21 & 2.0 & 4.36 & 0.7498 & 1 \\
\hline $\mathrm{A}_{2}$ & 20 & 0.9 & 5.9 & 0.2380 & 7 \\
\hline $\mathrm{A}_{3}$ & 19 & 0.72 & 6.9 & 0.2529 & 6 \\
\hline $\mathrm{A}_{4}$ & 21 & 1.63 & 5.27 & 0.6696 & 2 \\
\hline $\mathrm{A}_{5}$ & 20 & 0.90 & 6.9 & 0.3065 & 5 \\
\hline $\mathrm{A}_{6}$ & 21 & 1.63 & 4.18 & 0.6129 & 4 \\
\hline $\mathrm{A}_{7}$ & 22 & 1.54 & 5.63 & 0.6554 & 3 \\
\hline
\end{tabular}

Table 23: Alternatives from MOABC (Small-sized).

\begin{tabular}{l|l|l|l|l|l}
\hline $\begin{array}{l}\text { Altern- } \\
\text { ative }\end{array}$ & TCT & MWT & MWE & $\begin{array}{l}\text { Closeness } \\
\text { coefficient }\end{array}$ & Rank \\
\hline $\mathrm{A}_{1}$ & 104 & 8.96 & 10.27 & 0.1132 & 6 \\
\hline $\mathrm{A}_{2}$ & 97 & 7.54 & 10.60 & 0.1098 & 7 \\
\hline $\mathrm{A}_{3}$ & 99 & 7.19 & 12.86 & 0.1441 & 4 \\
\hline $\mathrm{A}_{4}$ & 106 & 9.8 & 9.47 & 0.8105 & 1 \\
\hline $\mathrm{A}_{5}$ & 101 & 6.54 & 21.29 & 0.2516 & 2 \\
\hline $\mathrm{A}_{6}$ & 109 & 10.39 & 5.03 & 0.0744 & 10 \\
\hline $\mathrm{A}_{7}$ & 99 & 7.37 & 15.01 & 0.1750 & 3 \\
\hline $\mathrm{A}_{8}$ & 107 & 10.15 & 8.76 & 0.1015 & 8 \\
\hline $\mathrm{A}_{9}$ & 99 & 7.19 & 11.21 & 0.1192 & 5 \\
\hline $\mathrm{A}_{10}$ & 111 & 11.05 & 4.29 & 0.0847 & 9 \\
\hline
\end{tabular}

Table 24: Alternatives from MOABC (Large-sized).

$\left.\left(\mathrm{A}_{8}=\mathrm{A}_{9}\right)\right)$ are repeated sequences. Hence 8 sequences are evaluated against the three objectives using chaoticTOPSIS. The calculation shows, the seventh sequence i.e. $\mathrm{A}_{8}\left(\right.$ or $\left.\mathrm{A}_{9}\right)$ is having rank 1 .

\section{DABC (Large-size Dataset)}

The large-sized synthetic dataset has again 3 decision matrices from DABC-I, DABC-II and DABC-III to be evaluated. Table 20 contains the decision matrix resulted from DABC-I. The 10 different alternatives (sequences) are having different closeness coefficient values and $\mathrm{A}_{6}$ is the highest ranked alternative.

The following decision matrix of Table 21 is the resulted optimized sequence of DABC-II for the large input data. Each alternative are processed to check the best set of functional values from the calculated closeness coefficient value. Here alternative $A_{9}$ is found to be superior one.

The non-dominated sequence of DABC-III is represented as the decision matrix in Table 22 with 10 alternatives. Two alternatives $\mathrm{A}_{3}$ and $\mathrm{A}_{4}$ are having same sequences. Hence altogether 9 different sequences are processed and according to chaotic-TOPSIS, $\mathrm{A}_{9}$ is the best one to be chosen by the decision maker.

\section{MOABC}

Table 23 contains the non-dominated sequence of MOABC for the small sized data set. It is consisting of 7 alternatives and chaotic-TOPSIS valuates $A_{1}$ as the suitable alternative for the decision maker among all. 
The non-dominated sequences of MOABC for the large data input is consisting of 10 sequences and are represented in Table 24. After checking the closeness coefficient values $\mathrm{A}_{4}$ is found as the best alternative among all.

The use of generating random numbers using different chaotic functions has been one of the remarkable techniques to tune the parameters in various algorithms in many fields, and this has become an active research topic in the recent optimization literature. By watching its advantage, we have introduced the concept of chaotic map to the standard TOPSIS, and have checked for the best alternative among a set of nondominated solutions. The decision makers will be definitely confident enough to take a right decision among the conflicting ones using the approach.

\section{Conclusions and future research}

The DABC and MOABC algorithms were coded and applied to the multiple instances of dataset ranging from 3 jobs with 3 machines to 10 jobs and 9 machines. In this paper, we considered the MOPFSSP under the multiple (three) criteria. The DABC algorithm is hybridized with a variant of iterated greedy algorithms employing a local search procedure based on insertion (), swap () and destruct- construct () neighborhood structures. In addition, we also presented an extended version of $\mathrm{ABC}$ algorithm to the proposed MOABC algorithm employed through a particular local search procedure with reduced complexity. Our proposal is having a significant application of DABC to check the time complexity of different local search procedures. Hence, we are motivated to use simple swap () operation in local search procedure in the MOABC algorithm. The performances of both the proposed algorithms were tested by using different instances of datasets and it has been shown that the performances of both DABC and MOABC algorithms are highly competitive with the best performing existing literature. Also we have extended our work to optimize the non-dominated solutions to a single optimal solution using chaotic-TOPSIS method to derive the optimal decision in the field of MCDM. The proposed approach will definitely help the decision makers to solve various MCDM problems in future. Further the problem of FSSP can be extended with nowait flowshop, blocking flowshop and no-idle flowshop, etc. Apart from three criteria we may practically have a many objective (MaO) PFSSP, which will obviously increase the number of non-dominated solutions in the search space. We may further work to find other effective ways to make a right decision for the decision makers to reach at a definite goal.

\section{Acknowledgment}

The data applied in this study is consisting of synthetic datasets ranges from small-size to large-sized ones.

\section{References}

[1] $\mathrm{K} \mathrm{R}$ Baker. Introduction to sequencing and scheduling. John Wiley \& Sons Inc. New York, 1974.

[2] S. M. Johnson. Optimal two- and three-stage production schedules with setup times included. Naval Research Logistics Quarterly, 1(1): 61-68, 1954. https://doi.org/10.1002/nav.3800010110

[3] D. S. Palmer. Sequencing jobs through a multistage process in the minimum total time-a quick method of obtaining a near optimum. Operations Research Society, 16(1): 101-107, 1965. https://doi.org/10.2307/3006688

[4] Jatinder N. D. Gupta. A functional heuristic algorithm for the flow shop scheduling problem. Operations Research Quarterly, 22(1)39-47, 1971. https://doi.org/10.2307/3008015

[5] Herbert G. Campbell, Richard A. Dudek and Milton L. Smith. A heuristic algorithm for the n-job, mmachine sequencing problem. Management Science, 16(10): .630-637, 1970. https://doi.org/10.1287/mnsc.16.10.b630

[6] David G. Dannenbring. An evaluation of flow shop sequencing heuristics. Management Science, 23(11):1174-1182, 1977. https://doi.org/10.1287/mnsc.23.11.1174

[7] Nawaz, Muhammad, Enscore Jr, E Emory and Ham, Inyong. A heuristic for the m-machine n-job flow shop sequencing problem. Omega, 11(1): 9195, 1983.

[8] S P Bansal. Minimizing the sum of completion times of $n$-jobs over m-machines in a flowshop: a branch and bound approach. AIIE Transactions, 9(3):306-311, 1977.

https://doi.org/10.1080/05695557708975160

[9] Chia-Shin Chung, James Flynn and Omer Kirca. A branch and bound algorithm to minimize the total flow time for m-machine permutation flowshop problems. International Journal of Production Economics, 79(3): 185-196, 2002. https://doi.org/10.1016/s0925-5273(02)00234-7

[10] Edward Ignall and Linus Schrage. Application of the branch and bound technique to some flow-shop scheduling problems. Operations Research, 13( 3): 400-412, 1965.

https://doi.org/10.1287/opre.13.3.400

[11] S.L. van de Velde. Minimizing the sum of the job completion times in the two-machine flow shop by Lagrangian relaxation. Annals of Operations Research, 26(1-4):257-268, 1990. https://doi.org/10.1007/bf03500931

[12] Willem J. Selen and David D. Hott. A mixedinteger goal-programming formulation of the standart flow-shop scheduling problem. Operation Research Society, 37(12) :1121-1128, 1986. https://doi.org/10.2307/2582302

[13] J. M. Wilson. Alternative formulations of a flowshop scheduling problem. Operation Research Society, 40(4): 395-399, 1989. https://doi.org/10.1057/jors.1989.58 
[14] Richard L. Daniels and Robert J. Chambers. Multiobjective flowshop scheduling. Naval Research Logistics, 37(6): 981-995, 1990.

https://doi.org/10.1002/1520-

6750(199012)37:6\%3C981::aidnav3220370617\%3E3.0.co;2-h

[15] Chandrasekharan Rajendran. Heuristics for scheduling in flowshop with multiple objectives. European Journal of Operation Research, 82(3):540-555, 1995. https://doi.org/10.1016/0377-2217(93)e0212-g

[16] Neelam Tyagi, R. P. Tripathi and A. B. Chandramouli. Three Machines Flowshop Scheduling Model with Bicriterion Objective Function, 9(48): 1-14, 2016. https://doi.org/10.17485/ijst/2016/v9i48/103012

[17] S.M. Mousavi, I. Mahdavi, J. Rezaeian and M. Zandieh. Bi-objective scheduling for the re-entrant hybrid flow shop with learning effect and setup times. Scientia Iranica, 25(4): 2233-2253, 2017. https://doi.org/10.24200/sci.2017.4451

[18] Karunakaran Chakravarthy and Chandrasekharan Rajendran. A heuristic for scheduling in flowshop with bi-criteria of makespan and maximum tardiness minimization. Production Planning \& Control, 10(7): 707-714, 1999. https://doi.org/10.1080/095372899232777

[19] R.K. Suresh and K.M. Mohanasundaram. Pareto archived simulated annealing for permutation flow shop scheduling with multiple objective. Proceedings of the 2004 IEEE Conference on Cybernetics and Intelligent Systems, 712-717, 2004. https://doi.org/10.1109/iccis.2004.1460675

[20] T.K. Varadharajan and Chandrasekharan Rajendran. A multi-objective simulated-annealing algorithm for scheduling in flowshops to minimize the makespan and total flowtime of jobs. Europian Journal of Operation Research, 167(3): 772-795, 2005. https://doi.org/10.1016/j.ejor.2004.07.020

[21] B. Shahul Hamid Khan and Kannan Govindan. Multi-objective simulated annealing algorithm for permutation flow shop scheduling problem. International Journal of Advanced Operations Management, 3(1):88-100, 2011. https://doi.org/10.1504/ijaom.2011.040661

[22] T. Loukil, J. Teghem and D. Tuyttens. Solving multi-objective production scheduling problems using metaheuristics. European Journal Operation Research, 161(1):42-61, 2005.

https://doi.org/10.1016/j.ejor.2003.08.029

[23] Xiangtao Li and Shijing Ma. Multi-objective memetic search algorithm for multi-objective permutation flow shop scheduling problem. IEEE Access, 4: 2154-2165, 2016. https://doi.org/10.1109/access.2016.2565622

[24] Fuyu Yuan, Xin Xu and Minghao Yin. A novel fuzzy model for multi-objective permutation flow shop scheduling problem with fuzzy processing time. Advances in Mechanical Engineering, 11(4):1-9, 2019.

https://doi.org/10.1177/1687814019843699

[25] S. Chandrasekaran, S. G. Ponnambalam, R. K. Suresh and N. Vijayakumar. Multi-objective particle swarm optimization algorithm for scheduling in flowshops to minimize makespan, total flowtime and completion time variance. IEEE Congress on Evolutionary Computation, 40124018, 2007.

https://doi.org/10.1109/cec.2007.4424994

[26] Vincent T'kindt, Nicolas Monmarché, Fabrice Tercinet and Daniel Laügt. An ant colony optimization algorithm to solve a 2-machine bicriteria flowshop scheduling problem. European Journal of Operation Research, 142(2):250-257, (2002). https://doi.org/10.1016/s0377-2217(02)00265-5

[27] Betul Yagmahan and Mehmet Mutlu Yenisey. Ant colony optimization for multi-objective flow shop scheduling problem. Computers and Industrial Engineering, 54(3):411-420, 2008. https://doi.org/10.1016/j.cie.2007.08.003

[28] B.M.T. Lin, C.Y. Lu, S.J. Shyu and C.Y. Tsai. Development of new features of ant colony optimization for flowshop scheduling. International Journal of Production Economics, 112( 2):742755, 2008. https://doi.org/10.1016/j.ijpe.2007.06.007

[29] M. Ziaee, S.J. Sadjadi, J.L. Bouquard. An Ant Colony Algorithm for the Flowshop Scheduling Problem. Journal of Applied Sciences. 8(21): 39383944, 2008. https://doi.org/10.3923/jas.2008.3938.3944

[30] Dervis Karaboga. An idea based on honey bee swarm for numerical optimization. Technical Report TR06. Computer Engineering Department. Erciyes University. Turkey, 2005.

[31] Dervis Karaboga and Bahriye Basturk. A powerful and efficient algorithm for numerical function optimization: artificial bee colony (ABC) algorithm. Journal of Global Optimization, 39(3):459-471, 2007.

https://doi.org/10.1007/s10898-007-9149-x

[32] Dervis Karaboga and B. Basturk. On the performance of artificial bee colony (ABC) algorithm. Applied Soft Computing, 8(1): 687-697, 2008.

https://doi.org/10.1016/j.asoc.2007.05.007

[33] Nurhan Karaboga. A new design method based on artificial bee colony algorithm for digital IIR filters. Journal of the Franklin Institute, 346 (4): 328-348, 2009.

https://doi.org/10.1016/j.jfranklin.2008.11.003

[34] Dervis Karaboga and Bahriye Akay. A comparative study of artificial bee colony algorithm. Applied Mathematics and Computation, 214 (1):108-132, 2009.

https://doi.org/10.1016/j.amc.2009.03.090

[35] Dervis Karaboga and Bahriye Akay. A survey: Algorithms simulating bee swarm intelligence. 
Artificial Intelligence Review, 31(1-4):68-85, 2009. https://doi.org/10.1007/s10462-009-9127-4

[36] Sangeeta Sharma and Pawan Bhambu. Artificial bee colony algorithm: A survey. International Journal of Computer Applications, 149(4):11-19, 2016. https://doi.org/10.5120/ijca2016911384.

[37] Pradeep Kumar Singh. A systematic review on artificial bee colony optimization technique. International Journal of Control Theory and Applications, 9(11): 5487-5500, 2016.

[38] Tuğçe Anılan, Ergun Uzlu, Murat Kankal and Omer Yuksek. The estimation of flood quantiles in ungauged sites using teaching-learning based optimization and artifcial bee colony algorithms. Scientia Iranica, 2017. https://doi.org/10.24200/sci.2017.4185

[39] Valery Tereshko. Reaction-diffusion model of a honeybee colony's foraging behaviour, in: PPSN VI. Proceedings of the Sixth International Conference on Parallel Problem Solving from Nature, Springer-Verlag, 807-816, 2000. https://doi.org/10.1007/3-540-45356-3_79

[40] Su-jun Zhang and Xing-sheng Gu. An effective discrete artificial bee colony algorithm for flow shop scheduling problem with intermediate buffers. Journal of Central South University, 22(9):3471-3484, 2015. https://doi.org/10.1007/s11771-015-2887-x

[41] Hoon-Shik Woo and Dong-Soon Yim. A heuristic algorithm for mean flowtime objective in flowshop scheduling. Computers and Operations Research, 25(3): 175-182. https://doi.org/10.1016/s0305-0548(97)00050-6

[42] I. Kassabalidis, M.A. El-Sharkawi, R.J. Marks, P. Arabshahi and A.A. Gray. Swarm intelligence for routing in communication networks. Global Telecommunications Conference, 3613-3617, 2001.

https://doi.org/10.1109/glocom.2001.966355

[43] M. Fatih Tasgetiren, Quan-Ke Pan, P.N. Suganthan and Angela H-L Chen. A discrete artificial bee colony algorithm for the total flowtime minimization in permutation flowshops. Information Sciences, 181(16): 3459-3475, 2011. https://doi.org/10.1016/j.ins.2011.04.018

[44] Bertrand Mareschal. Weight stability intervals in multicriteria decision aid. Europian Journal of Operation Research, 33(1) :54-64,1988. https://doi.org/10.1016/0377-2217(88)90254-8

[45] Dervis Karaboga, Beyza Gorkemli, Celal Ozturk and Nurhan Karaboga. A comprehensive survey: Artificial bee colony (ABC) algorithm and applications. Artificial Intelligence Review, 42(1): 21-57, 2014.

https://doi.org/10.1007/s10462-012-9328-0

[46] E. Taillard, E. Benchmarks for basic scheduling problems. European Journal of Operational Research, 64(2):278-285, 1993. https://doi.org/10.1016/0377-2217(93)90182-m
[47] Peng Wang, Yang Li, Yong-Hu Wang and ZhouQuan Zhu. A new method Based on TOPSIS and Response Surface Method for MCDM problems with interval numbers. Mathematical Problems in Engineering. Article ID 938535, 2015:1-11, 2015. https://doi.org/10.1155/2015/938535

[48] Elissa Nadia Madi, Jonathan M. Garibaldi and Christian Wagner. An exploration of issues and limitations in current methods of TOPSIS and fuzzy TOPSIS. IEEE International Conference on Fuzzy Systems, 2098-2105, 2016. https://doi.org/10.1109/fuzz-ieee.2016.7737950

[49] Alireza Sotoudeh-Anvari, Seyed Jafar Sadjadi, Seyed Mohammad Hadji Molana and Soheil SadiNezhad. A stochastic multi-objective model based on the classical optimal search model for searching for the people who are lost in response stage of earthquake. Scientia Iranica, 26(3):1842:1864, 2019.

https://doi.org/10.24200/sci.2018.20226

[50] Edmundas Kazimieras Zavadskas, Abbas Mardani, Zenonas Turskis, Ahmad Jusoh and Khalil MD Nor. Development of TOPSIS method to solve complicated decision-making problems: An overview on developments from 2000 to 2015. International Journal of Information Technology \& Decision Making, 15 (3): 1-38, 2016. https://doi.org/10.1142/s0219622016300019

[51] Bing Wu, Likang Zong, Xinping Yan and C. Guedes Soares. Incorporating evidential reasoning and TOPSIS into group decision-making under uncertainty for handling ship without command. Ocean Engineering,164: 590-603, 2018. https://doi.org/10.1016/j.oceaneng.2018.06.054

[52] Ching-Lai Hwang and Kwangsun Yoon. Multiple Attribute Decision Making. Springer-Verlag, Berlin, 58-191, 1981. https://doi.org/10.1007/978-3-642-48318-9_3

[53] Sheldon M. Belenson and Kailash C. Kapur. An algorithm for solving multi-criterion linear programming problems with examples. Operational Research Quarterly, 24(1): 65-77, 1973. https://doi.org/10.2307/3008036

[54] Milan Zelany. A concept of compromise solutions and the method of the displaced ideal' Computers and Operations Research, 1( 3-4): 479-496,1974. https://doi.org/10.1016/0305-0548(74)90064-1

[55] Gyutai Kim, Chan S Park and K.Paul Yoon. Identifying investment opportunities for advanced manufacturing systems with comparative-integrated performance measurement. International Journal of Production Economics, 50(1): 23-33, 1997. https://doi.org/10.1016/s0925-5273(97)00014-5

[56] Steven Cheng, Christine W. Chan and Guo H. Huang. Using multiple criteria decision analysis for supporting decision of solid waste management. Journal of Environmental Science and Health. Part A, 37(6): 975-990, 2002. https://doi.org/10.1081/ese-120004517

[57] Stelios H. Zanakis, Anthony Solomon, Nicole Wishart and Sandipa Dublish. Multi-attribute 
decision making: A simulation comparison of selection methods. European Journal of Operational Research, 107(3):507-529, 1998.

https://doi.org/10.1016/s0377-2217(97)00147-1

[58] Leandro dos Santos Coelho and Viviana Cocco. Use of chaotic sequences in a biologically inspired algorithm for engineering design and optimization. Expert Systems with Applications, 34(3):19051913, 2008. https://doi.org/10.1016/j.eswa.2007.02.002

[59] Bilal Altlas. Chaotic bee colony algorithms for global numerical optimization. Expert systems with applications, 37(8): 5682-5687, 2010. https://doi.org/10.1016/j.eswa.2010.02.042

[60] Bilal Altlas. Chaotic harmony search algorithms. Applied mathematics and computation, 216( 9): 2687-2699, 2010. https://doi.org/10.1016/j.amc.2010.03.114

[61] Amir Hossein Gandomi, Gun Jin Yun, Xin-She Yang and Siamak Talatahari. Chaos-enhanced accelerated particle swarm algorithm. Communications in Nonlinear Science and Numerical Simulation, 18(2):327-340, 2013. https://doi.org/10.1016/j.cnsns.2012.07.017

[62] Amir Hossein Gandomi, X.-S. Yang, S. Talatahari and A.H. Alavi. Firefly algorithm with chaos. Communications in Nonlinear Science and Numerical Simulation, 18(1): 89-98, 2013. https://doi.org/10.1016/j.cnsns.2012.06.009

[63] Golnar Gharooni-fard, Fahime Moein-darbari, Hossein Deldari and Anahita Morvaridi. Scheduling of scientific workflows using a chaos-genetic algorithm. Procedia Computer Science, 1(1): 14451454, 2010. https://doi.org/10.1016/j.procs.2010.04.160

[64] S. Talatahari, B. Farahmand Azar, R. Sheikholeslami and A.H. Gandomi. Imperialist competitive algorithm combined with chaos for global optimization. Communications in Nonlinear Science and Numerical Simulations, 17(3): 13121319, 2012. https://doi.org/10.1016/j.cnsns.2011.08.021

[65] Wei Gong and Shoubin Wang. Chaos ant colony optimization and application. 4th Inter-national Conference on Internet Computing for Science and Engineering, 301-303, 2009. https://doi.org/10.1109/icicse.2009.38

[66] Ji Mingjun and Tang Huanwen. Application of chaos in simulated annealing. Chaos, Solitons \& Fractals, 21(4): 933-941, 2004.

https://doi.org/10.1016/j.chaos.2003.12.032

[67] Amir H. Gandomi and Xin-She Yang. Chaotic bat algorithm. Journal of Computational Science, 5(2):224-234, 2014.

https://doi.org/10.1016/j.jocs.2013.10.002 